\title{
An Insight into the Gelatinization Properties Influencing the Modified Starches Used in Food Industry: A review
}

\author{
Ishita Chakraborty ${ }^{1} \cdot$ Pooja $\mathrm{N}^{1} \cdot$ Sib Sankar Mal $^{2} \cdot$ Uttam C. Paul $^{3} \cdot$ Md. Hafizur Rahman $^{4} \cdot$ Nirmal Mazumder $^{1}(\mathbb{C}$
}

Received: 18 August 2021 / Accepted: 3 January 2022 / Published online: 3 February 2022

(c) The Author(s) 2022

\begin{abstract}
Native starch is subjected to various forms of modification to improve its structural, mechanical, and thermal properties for wider applications in the food industry. Physical, chemical, and dual modifications have a substantial effect on the gelatinization properties of starch. Consequently, this review explores and compares the different methods of starch modification applicable in the food industry and their effect on the gelatinization properties such as onset temperature $\left(T_{o}\right)$, peak gelatinization temperature $\left(T_{p}\right)$, end set temperature $\left(T_{c}\right)$, and gelatinization enthalpy $(\Delta H)$, studied using differential scanning calorimetry (DSC). Chemical modifications including acetylation and acid hydrolysis decrease the gelatinization temperature of starch whereas cross-linking and oxidation result in increased gelatinization temperatures. Common physical modifications such as heat moisture treatment and annealing also increase the gelatinization temperature. The gelatinization properties of modified starch can be applied for the improvement of food products such as ready-to-eat, easily heated or frozen food, or food products with longer shelf life.
\end{abstract}

Keywords Starch $\cdot$ Modified starch $\cdot$ Differential scanning calorimetry $\cdot$ Gelatinization

\section{Introduction}

Starch is a widely available, biodegradable natural, and hydrophilic polymeric carbohydrate derived from plants. Major sources of starch include cereals, roots, tubers, and legumes, which contain nearly $70 \%$ of starch by dry weight (Alcázar-Alay \& Meireles, 2015; Wang et al., 2020). Starch has two polysaccharide components - amylose (15-30\%) and amylopectin (70-85\%) (Wang et al., 2020). The ratio of amylose and amylopectin in starch differs based on their botanical source. Amylose is a linear chain of $\alpha$-D-glucose

Nirmal Mazumder

nirmaluva@gmail.com

1 Department of Biophysics, Manipal School of Life Sciences, Manipal Academy of Higher Education, Karnataka, Manipal 576104, India

2 Materials and Catalytic Laboratory, Department of Chemistry, NITK, Karnataka, Mangalore 575025, India

3 Smart Materials, Istituto Italiano di Tecnologia, via Morego 30, Genova 16163, Italy

4 Laboratory of Nano-Bio and Advanced Materials Engineering, Department of Chemical Engineering, Jashore University of Science Technology, Jashore, Bangladesh linked by $\alpha(1-4)$ glycosidic linkage whereas, in amylopectin, glucose units are linked linearly with $\alpha(1-4)$ glycosidic linkage, but branching occurs by $\alpha(1-6)$ glycosidic linkage frequently at 24 to 30 glucose units. Internally, starch granules are composed of alternating semi-crystalline (amylopectin) and amorphous (amylose) rings, which are referred to as growth rings. These rings are about $100-400 \mathrm{~nm}$ thick. Starch has several applications in various industries including the textile, pharmaceutical, and food industries. In the food industry, starch is either used in unprocessed native form (extracted from the plant) or in processed/modified form (Mathobo et al., 2021; Ulbrich \& Flöter, 2019; Wang et al., 2019a, b, c). Unprocessed or raw native starches are not widely used in advanced food industries. This is because they possess low thermal and shear resistance, and higher retrogradation tendency which is the main reason behind the staling of food products (Wang et al., 2019a, b, c). To overcome these liabilities, starch modification is an obligation to alter its physicochemical properties based on the requirement. Starch modifications may be of different types like chemical, physical, or dual modifications (Dai et al., 2020). The chemical modification alters the physiochemical properties of starch by introducing new chemical or functional groups in starch without altering the shape and 
size of starch granules. Physical modifications change the morphology and structure of starch influenced by physical factors such as moisture, temperature, pressure, $\mathrm{pH}$ change, radiation treatment, and ultrasonic treatment. Dual modification is when starch is modified using two different methods. Compared with physical modifications, chemical methods provide more options for the functionalization of starch and therefore broaden the application field significantly. However, those treatments can be harmful to the environment (Fan \& Picchioni, 2020). Modified starch is widely used in the food industry as a fat replacer, thickener, stabilizer, or textural modifier. Starch is modified by hydrolysis to form a fat replacer such as maltodextrin. It is widely used in low-fat spread, mayonnaise, and ice cream (Chen et al., 2020). Modified starch is also used as a water-soluble gelling agent to stabilize high-shear emulsions such as mayonnaise and salad dressings (Depree \& Savage, 2001). Several studies have also been conducted on the use of modified starch to improve the textures of food products. Bread crumbs prepared with phosphorylated cross-linked tapioca starch exhibit a dry texture compared to bread produced from flour substituted with native hydroxypropylated and acetylated tapioca starches (Abbas et al., 2010). The limits of starch modification, use, and labeling are distinctly specified by the US Code of Federal Regulation and its consumption does not usually exhibit any side effects (Abbas et al., 2010). However, a rare case study had reported that acetylated distarch phosphate starch, a modified starch used in some baby foods, leads to diarrhea. In the experiment, 20 normal infants and 21 toddlers aged 8-24 months were fed with formulae that contained $8 \%$ native or $8 \%$ acetylated distarch phosphate waxy maize starch. The study concluded that acetylated distarch phosphate starch consumption contributed to increased breath hydrogen and loose stools (Lebenthal-Bendor et al., 2001).

Modifications, whether physical, chemical, or dual, end up affecting the gelatinization parameters of starch making it suitable for several purposes that the native starch may be unable to fulfill. When starch is heated with water, intermolecular bonds within the starch molecule are broken, and this phenomenon is known as gelatinization. The process of gelatinization is exceedingly influenced by starch modifications (Shi et al., 2020). Gelatinization is an important phenomenon when it comes to the cooking properties, texture, and palatability of starch-based food products. Starch gelatinization disrupts the molecular orderliness within the granule and results in granular swelling, crystallite melting, loss of birefringence, increase in viscosity, and solubilization. Figure 1A depicts the mechanism of starch gelatinization from various sources in the presence of water and heat. This review elaborates on the applications of various modified starch in food industries and their gelatinization properties studied using differential scanning calorimetry (DSC). Finally, the purpose of this review will contribute to develop specialized modified starch-based food products with specific applications of modification methods including improved texture, better freeze-thaw stability, and reduced syneresis.

\section{Factors Affecting Gelitinization of Starch}

The gelatinization property of starches is a very crucial factor in the food industry. The differential scanning calorimetry (DSC) is a very powerful technique to study the effect of modifications on the thermal behavior, gelatinization, and structural organization of starch granules. During gelatinization, DSC measures the degree of disruption of hydrogen bonds within the starch granules and quantifies the heat energy that is represented by enthalpy (Liu et al., 2019). A DSC instrument may be of two types, namely, heat flux DSC and power compensation DSC. In a heat flux DSC, the difference in temperature between the reference and the given sample is measured as a function of temperature. On the other hand, power compensation DSC directly measures the change in enthalpy of the sample as a function of time (Menczel \& Kohl, 2020). Figure 1B depicts a commonly used typical heat flux DSC instrument with a gelatinization curve of starch.

Gelatinization is a semi-cooperative or cooperative process in which the starch breaks down in presence of water and heat; first, the amorphous region (amylose) hydrates and swells, straining and tearing away crystalline regions (amylopectin). Gelatinization begins in the amorphous regions since the hydrogen bonds are weaker in this domain. This process is initiated at the hilum of the starch granule and slowly spreads to the periphery. The gelatinization properties depend on the molecular structure of amylopectin and the ratio of amylopectin to amylose (Abbas et al., 2010). Therefore, starch gelatinization is an "order-to-disorder transition" that results in loss of birefringence, increased swelling power, and solubility (Palanisamy et al., 2020). This action of gelatinization stresses the crystallites so that they cooperatively melt at a lower temperature. Structural relationships between the amorphous and crystalline domains of the starch granule are accountable for the peak temperature of gelatinization, and the sharpness of the gelatinization endotherm. Starch gelatinization is obtained as an endotherm as starch granules consume heat energy resulting in disruption of their molecular order. However, the peaks of the endotherm may be up or down, due to the instrument program, depending on the manufacturer. Onset $\left(T_{o}\right)$ and end set/ ceasing $\left(T_{c}\right)$ refer to the temperature of onset and ceasing of gelatinization process. The peak temperature of gelatinization $\left(T_{p}\right)$ is defined as the temperature at the peak apex of the gelatinization endotherm of starch. Gelatinization enthalpy $(\Delta H)$ shows the loss of molecular organization in the granule 

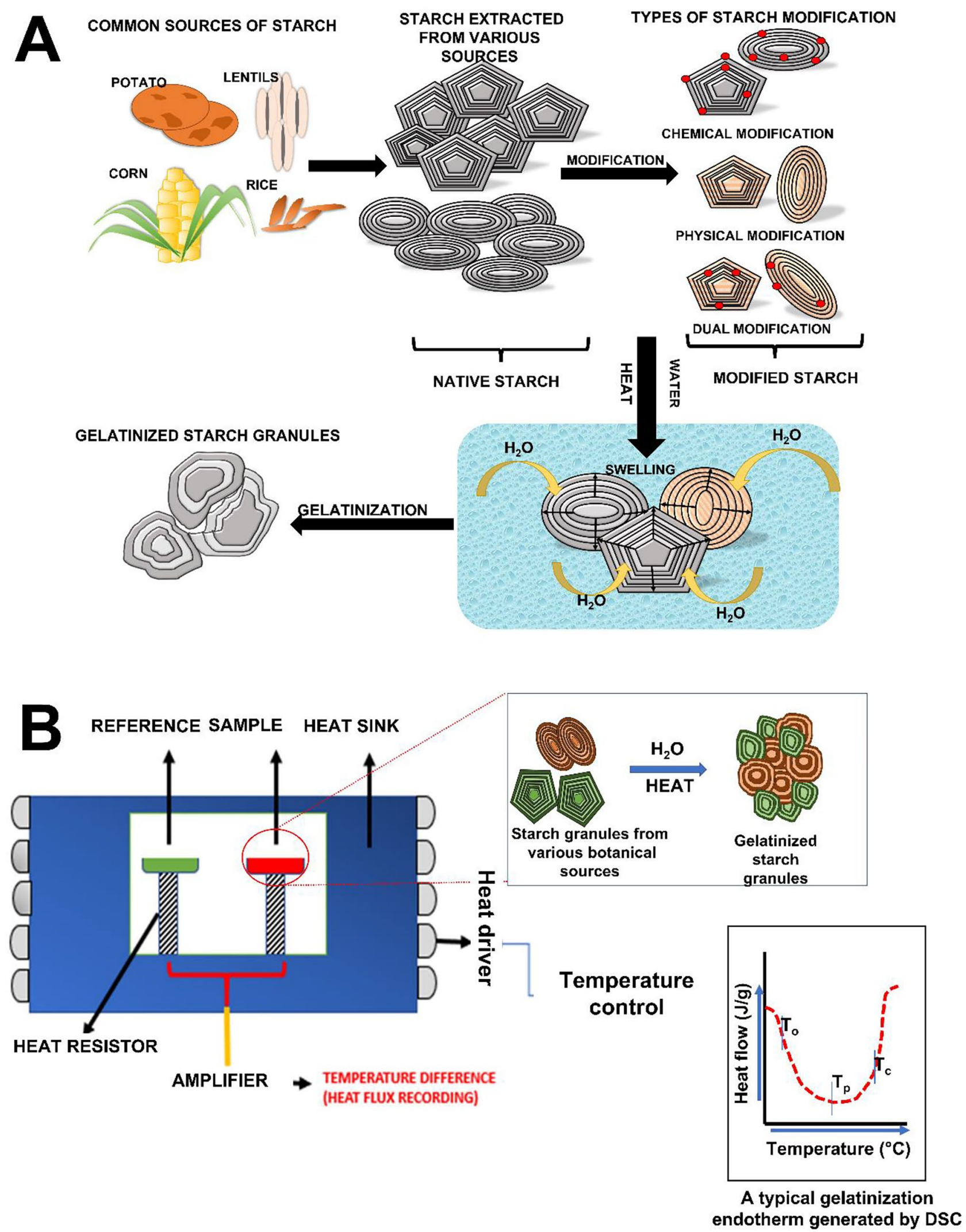

Fig. 1 (A) Gelatinization of native and modified starch from various sources in presence of water and heat. (B) Working mechanism of a heat flux DSC instrument with typical gelatinization curve of starch 
(Alvani et al., 2011). The palatability, structure, and texture of starch-based food are mostly affected by functional properties including starch swelling and gelatinization behavior. Interpreting the mechanisms affecting the gelatinization of the starch is essential for developing food formulations with enhanced nutritional composition, such as sugar reduction and fiber enrichment (Renzetti et al., 2021). The phenomenon of starch gelatinization depends on various factors are discussed in the following.

\section{Variety and Origin of Starch}

The gelatinization properties of starch largely depend on various factors such as their botanical origin, amylose-amylopectin ratio, granular shape and size, relative crystallinity, and moisture content (Govindaraju et al., 2020). The most common sources of starch are corn, wheat, rice, sorghum, potato, and barley (Hu et al., 2020). A previous study has reported that changes in gelatinization properties of starch occur primarily based on particle size where smaller starch granules result in decreased thermal stability (Hong et al., 2020). Another study has reported that large granules are gelatinized first at higher temperatures followed by smaller granules at lower temperatures and a broader gelatinization range (Vermeylen et al., 2005). In a recent study, ten indigenous rice varieties from Northeast India were subjected to gelatinization study using DSC. All ten varieties exhibited variations in $T_{o}, T_{p}, T_{c}$, and $\Delta H$ values. These variations were accredited to factors mentioned above including the architecture of the starch granules, amylose-amylopectin content, and crystallinity (Govindaraju et al., 2021). According to Zhu and Liu (2020), the internal molecular structure of amylopectin plays an important role in starch gelatinization and concluded that a more ordered structure of amylopectin in starch results in higher thermal stability and melting enthalpy changes of the starches.

\section{Moisture and Temperature}

Moisture content also affects the gelatinization of native starch. In excess water, as temperature rises, the starch crystals melt cooperatively as a single peak at higher gelatinization temperature $\left(T_{p 1}\right)$. In limited water, starch crystals melt partly, and the remaining crystals produce a second peak at higher temperatures $\left(T_{p 2}\right)$. A study reported that rice and maize starches displayed gelatinization temperatures ranging between 58.9 and $72.4{ }^{\circ} \mathrm{C}$ (rice) and 64.3 and $77.2^{\circ} \mathrm{C}$ (maize). Further, starch that has been pre-treated with heat-water will have an increased gelatinization temperature. It was reported that the degree and temperature of gelatinization of 5\% (w/w) tapioca, corn, potato, and wheat starch suspensions increased with an increase in treatment temperature in the range between $25^{\circ} \mathrm{C}$ (Bauer \& Knorr, 2005). Corn starch was treated at specific temperatures ranging between 35 and $90{ }^{\circ} \mathrm{C}$ for $30 \mathrm{~min}$. An increase in $T_{p}$ and $\Delta H$ was observed with the increasing temperature of treatment (Jackson \& Ratnayake, 2006). Another study revealed that a high-temperature exposure during the rice grain filling stage led to an increase in gelatinization temperatures of rice starch, irrespective of rice genotypes. Studies have reported that the increase in gelatinization temperatures is usually accredited cooperative melting of starch crystallites mediated by water (Liu et al., 2017).

\section{Concentration of Sugar and Salt}

Sugar is known to increase the temperature of starch gelatinization (Zhang et al., 2020), (Table 1) since it limits the availability of water to starch. When sugar is placed in water, it binds some of the water and lowers the free water in the system. Research suggests that the chemical nature and concentration of salts can cause either an increase or a decrease in gelatinization temperature and enthalpy of starch. A study reported that the increasing concentrations of $\mathrm{NaCl}$ to native potato starch exhibited a rise in gelatinization temperature and a decrease in $\Delta \mathrm{H}$ (Shi et al., 2019).

\section{Lipid and Protein Content}

Starch, lipids, and proteins are three macronutrients in the human diet that provide the body with energy. Lipids and protein content influence starch gelatinization properties. In a study, three rice varieties, namely, high-lipid rice (GZ1), a low apparent amylose content (GZ93), and parent rice (R7954), were employed for thermal characterization using DSC. It was noted that the $\Delta H$ value of GZ1 with high lipid content was lower than those of R7954 and GZ93. However, the removal of lipids significantly increased the $\Delta H$ value (Zhang et al., 2019a, b, c). Starch and lipids form inclusion complexes or starch-lipid complexes either naturally or during repeated heating and cooling, commonly occurring during food processing. The formation of starch-lipid complexes with the amylose component of starch alters the gelatinization properties of starch. On the other hand, proteins bind to starch molecules, preventing the escape of exudates through the granule surface. The interaction between protein and starch is mainly electrostatic, between the anionic groups of the starch and the positively charged groups of the protein. The protein-starch interactions in bulk solutions and at interfaces have an important influence on the stability properties of food dispersions. This protein-starch interaction results in increased gelatinization temperature of starch. A recent study revealed the effect of starch-protein interactions on the thermal properties of starch using DSC. Obtained results showed that corn starch-whey protein isolate (WPI) blends exhibited delayed gelatinization as the swelling process was restricted. This was accredited to 

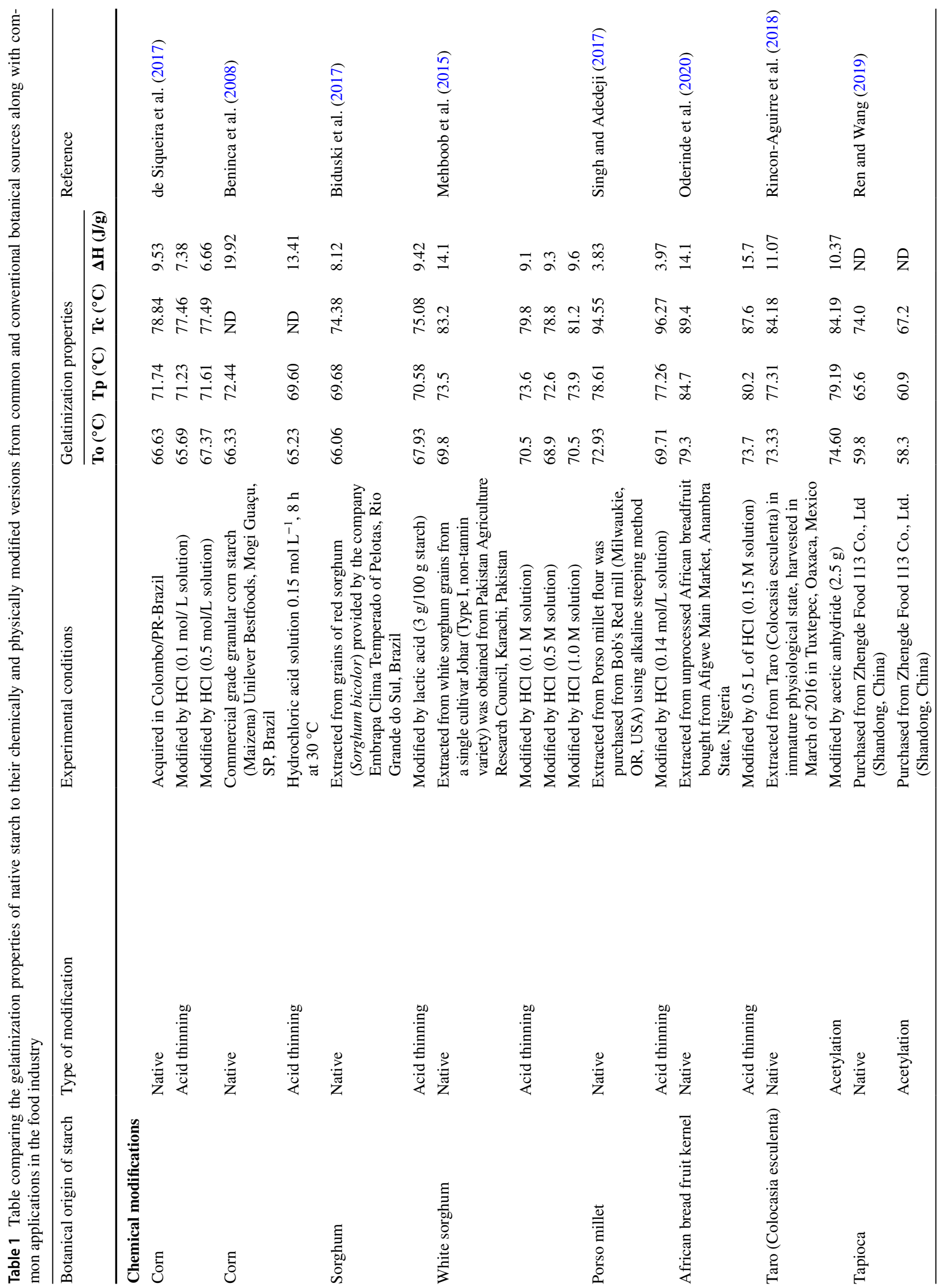


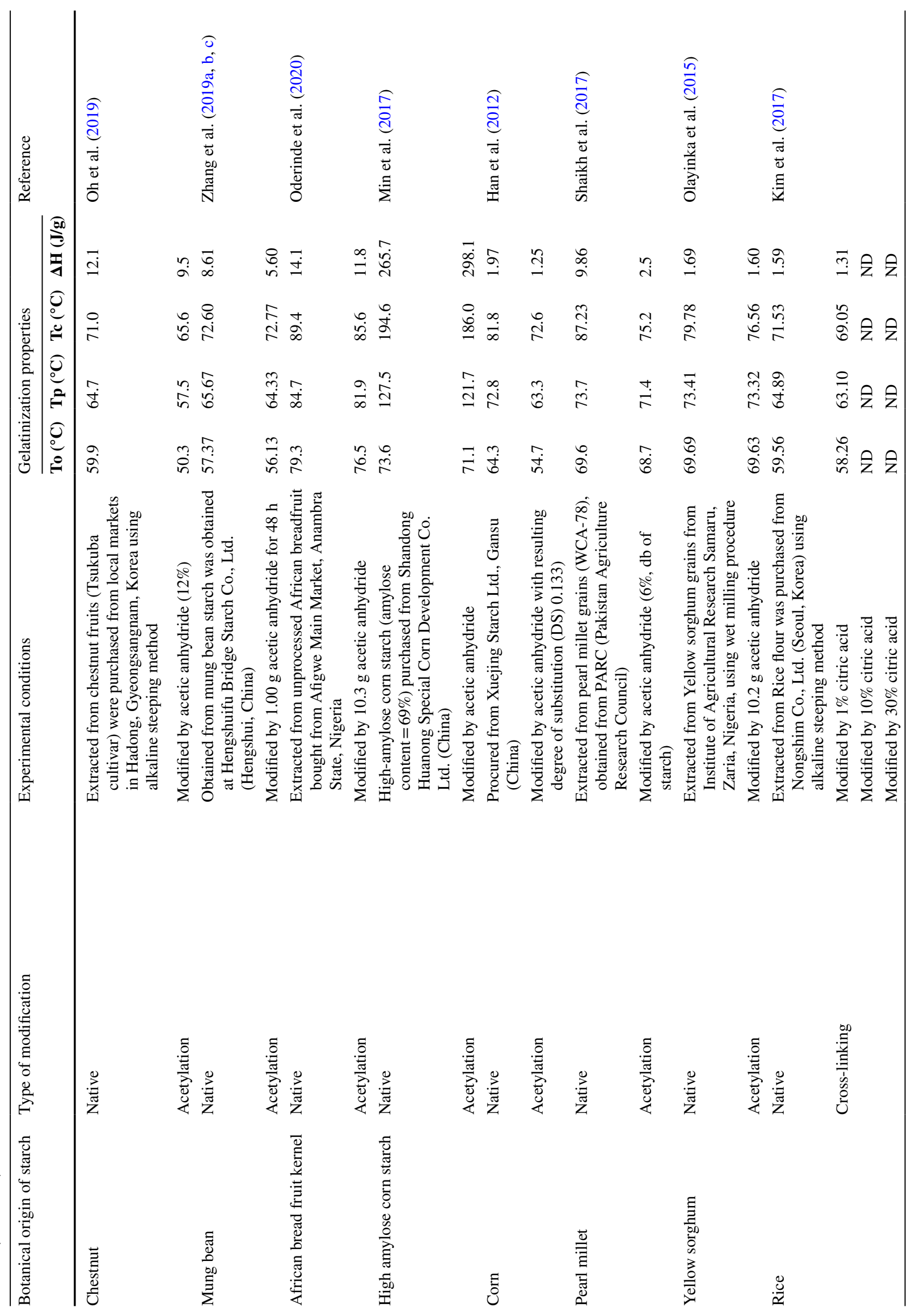




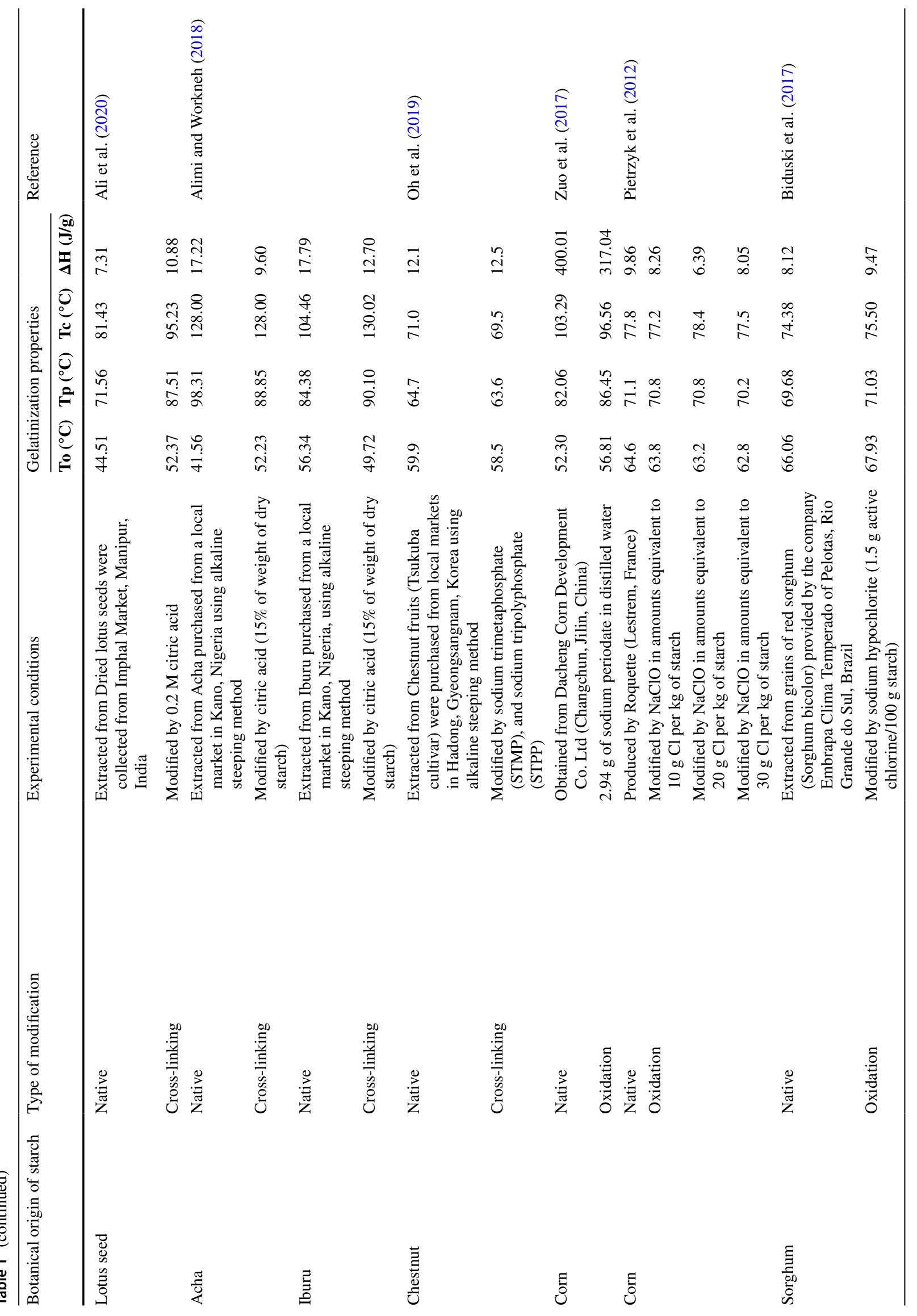




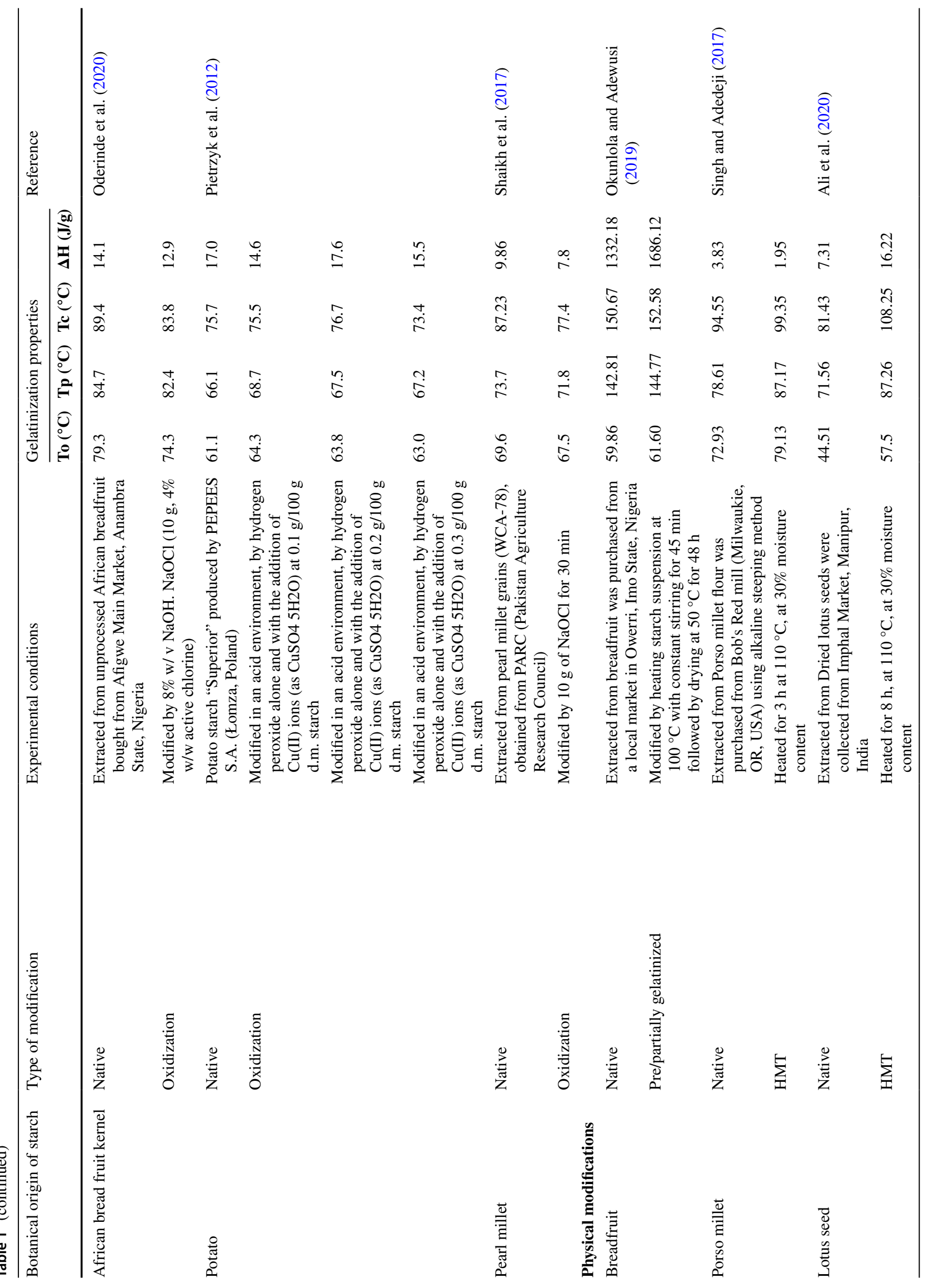




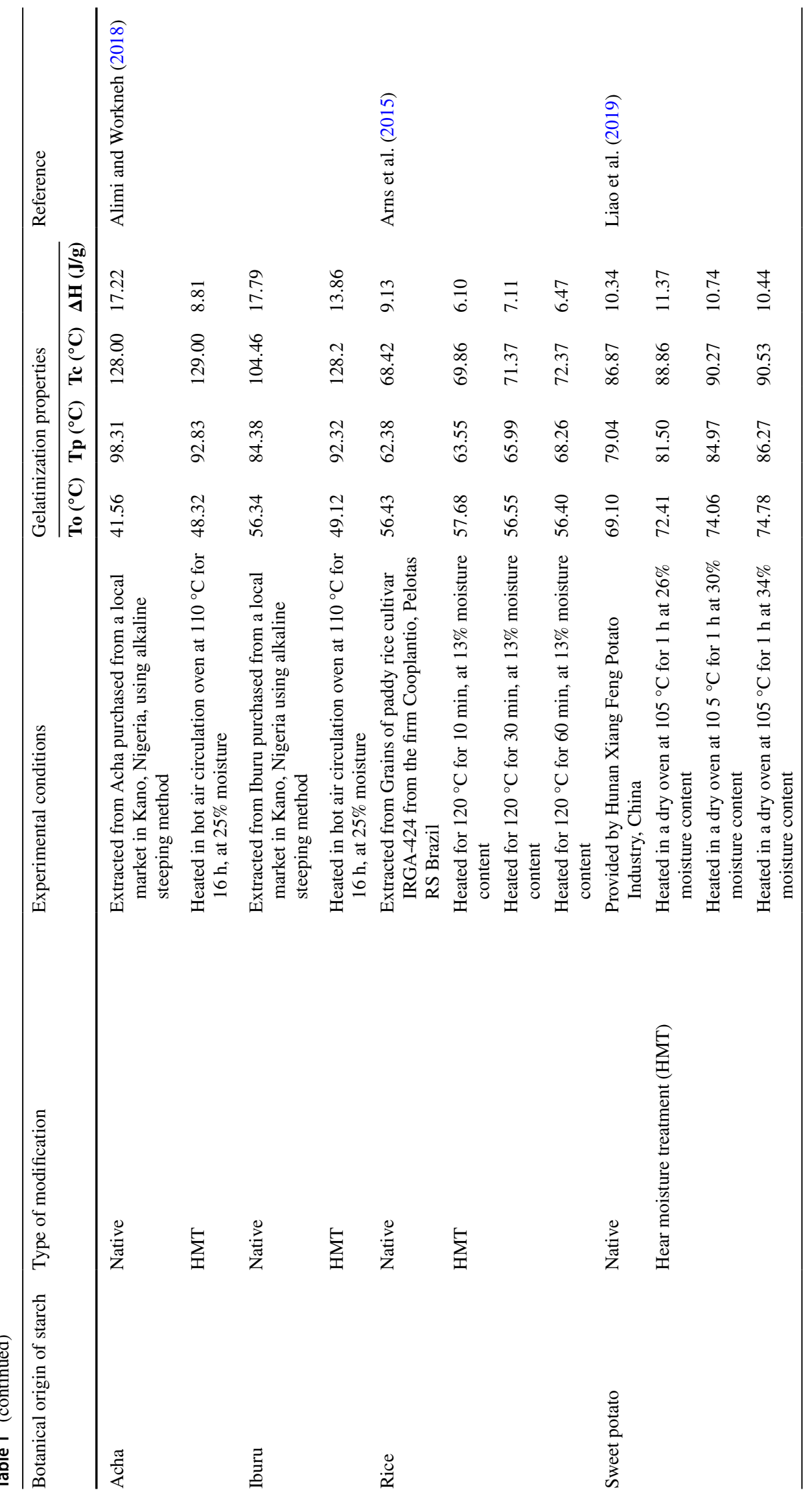




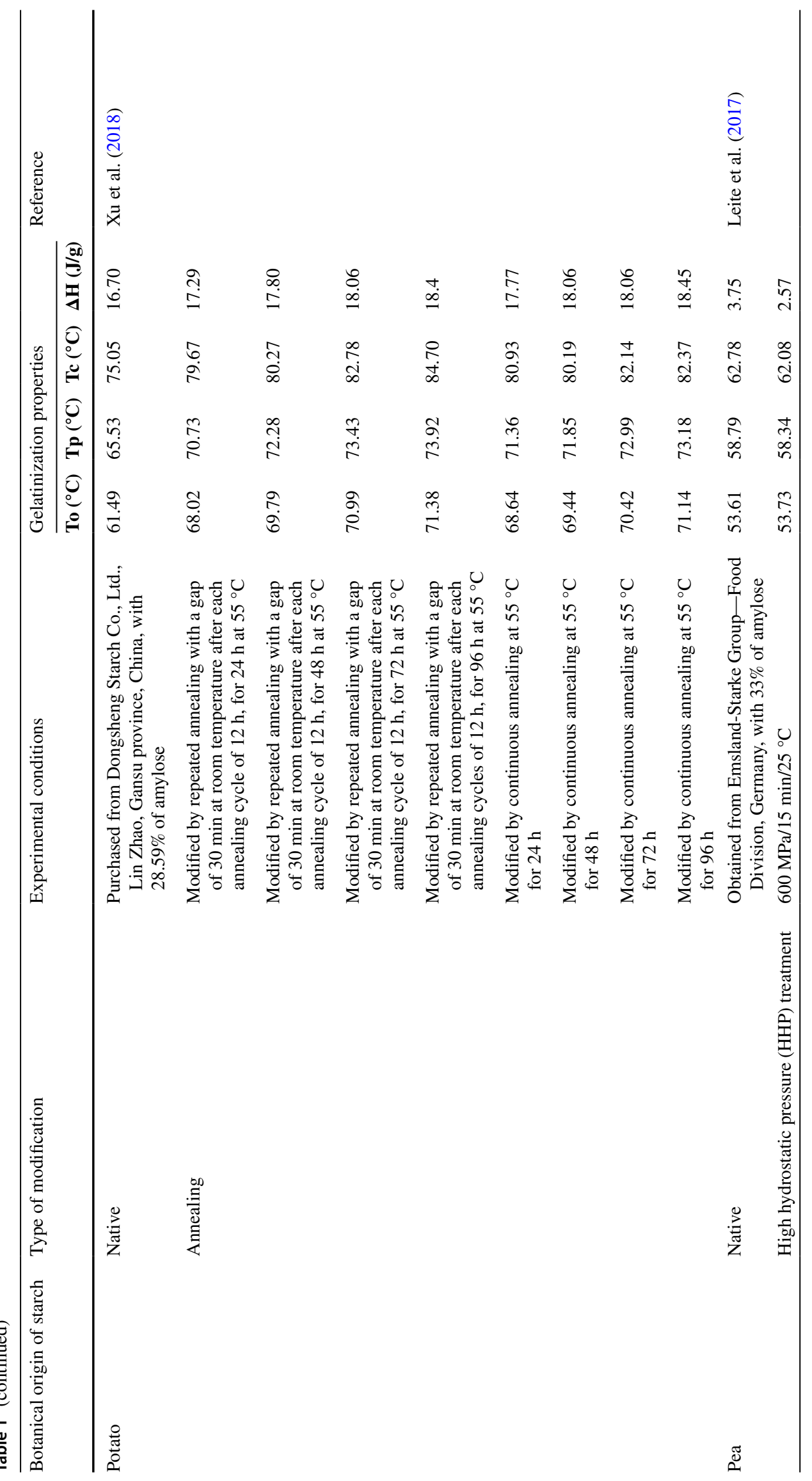




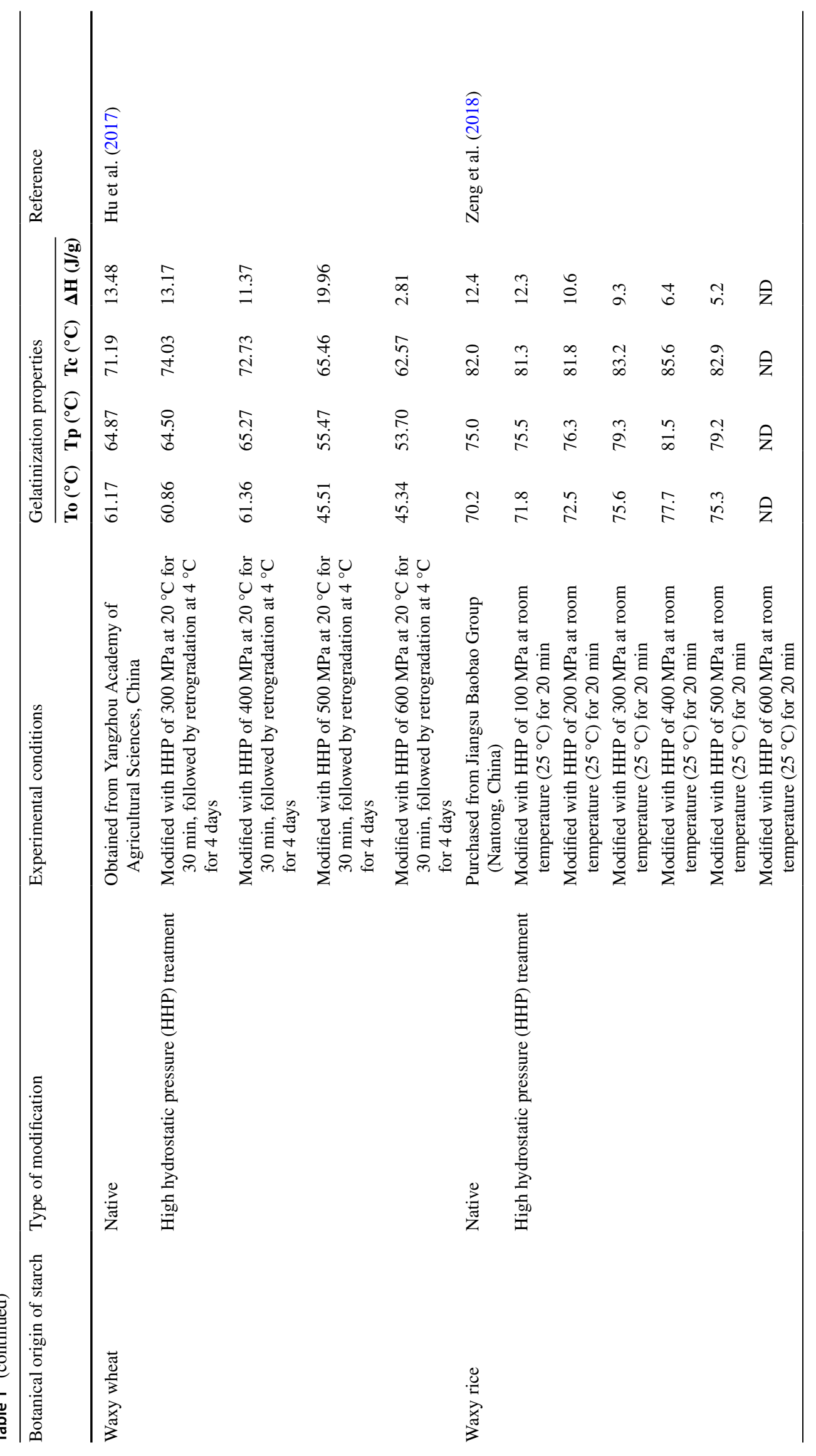




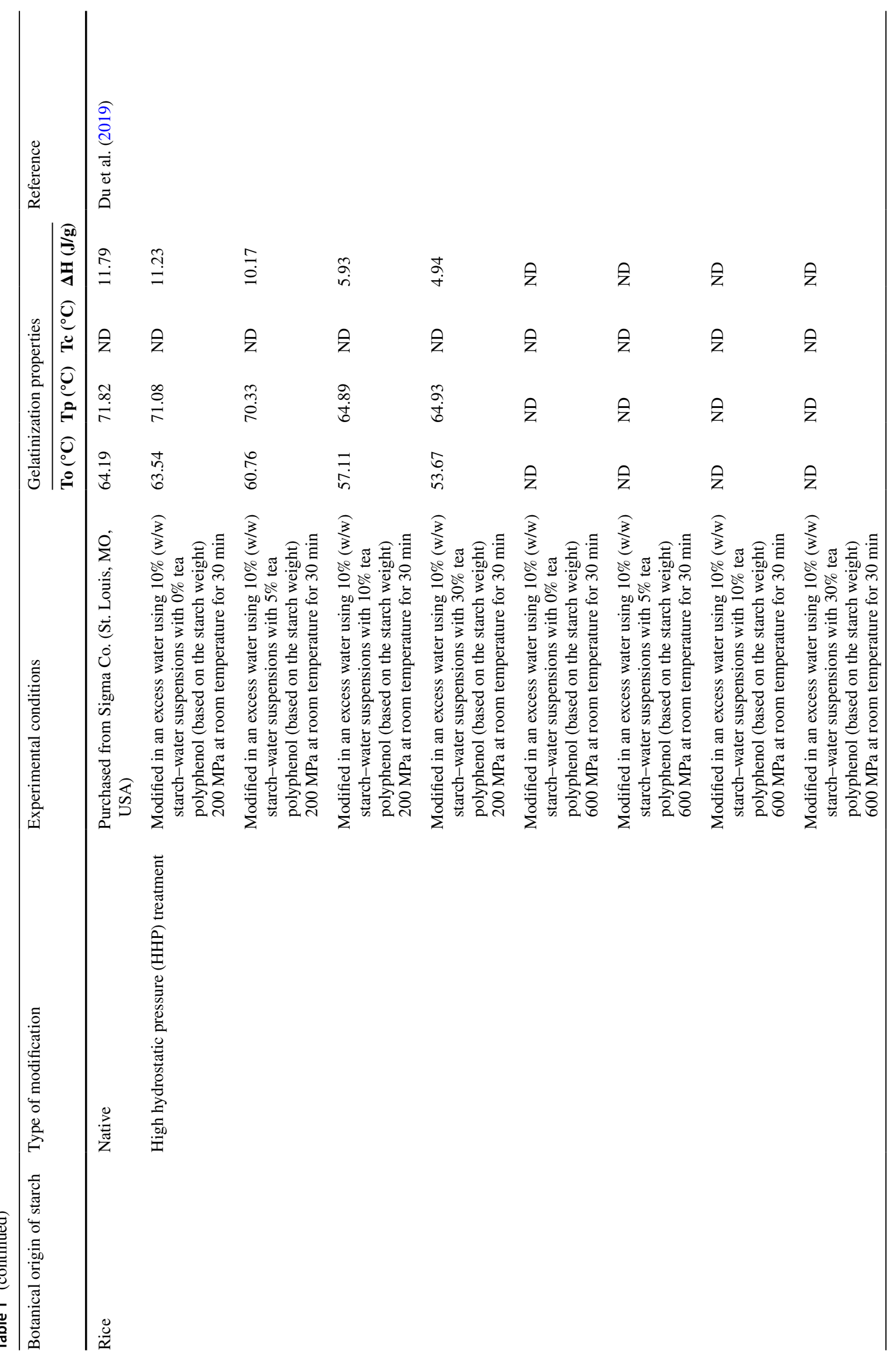




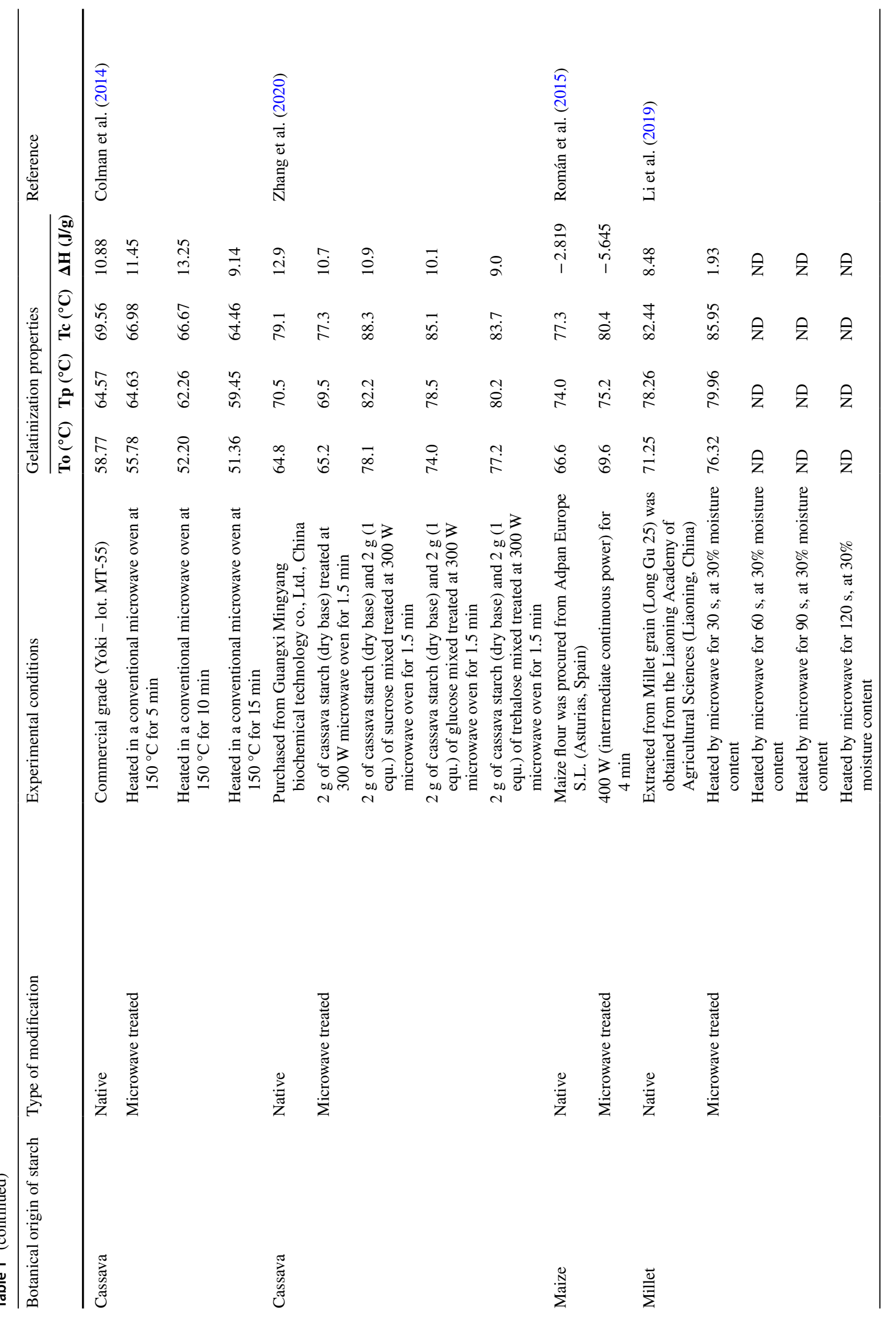




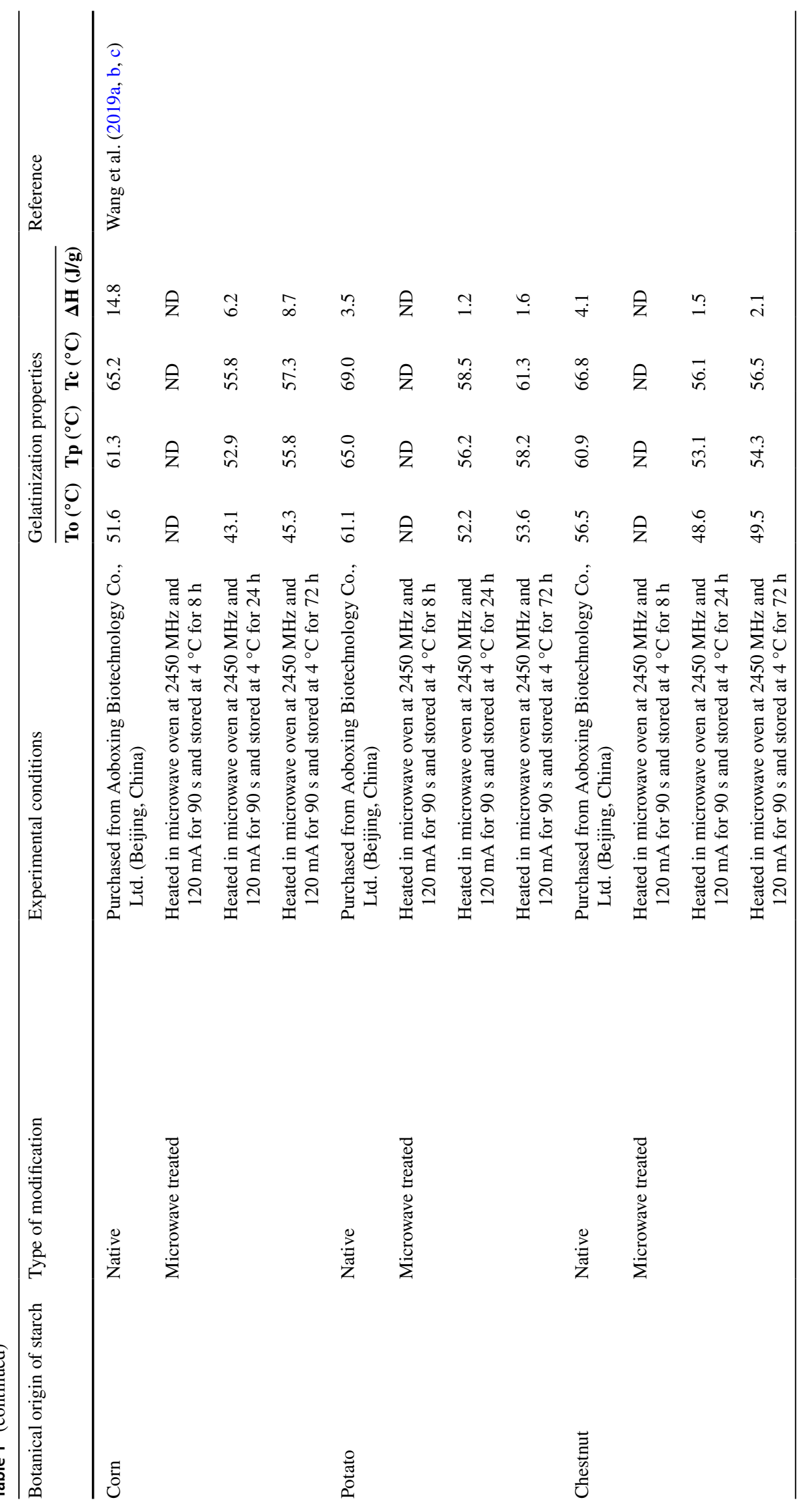




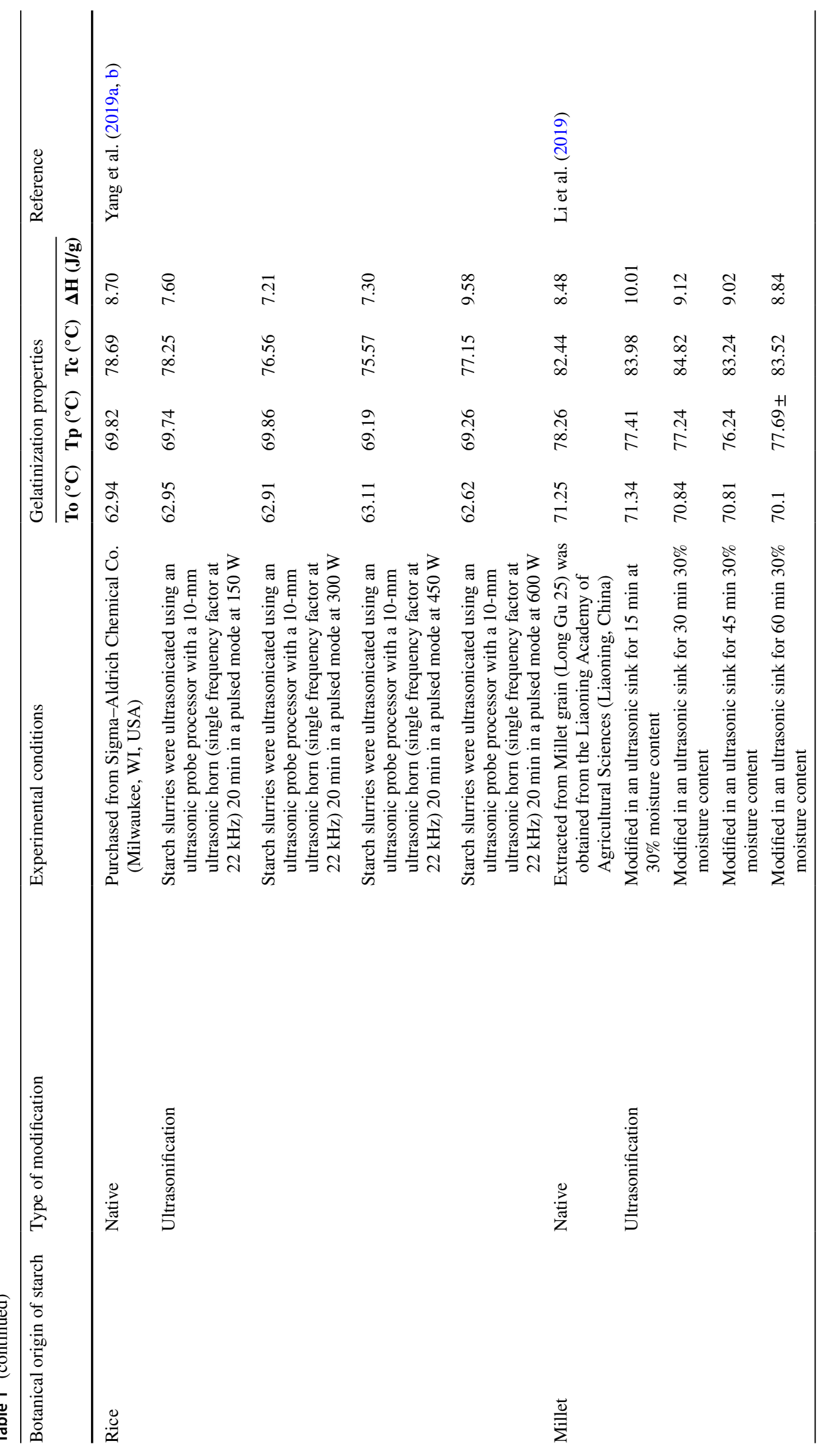




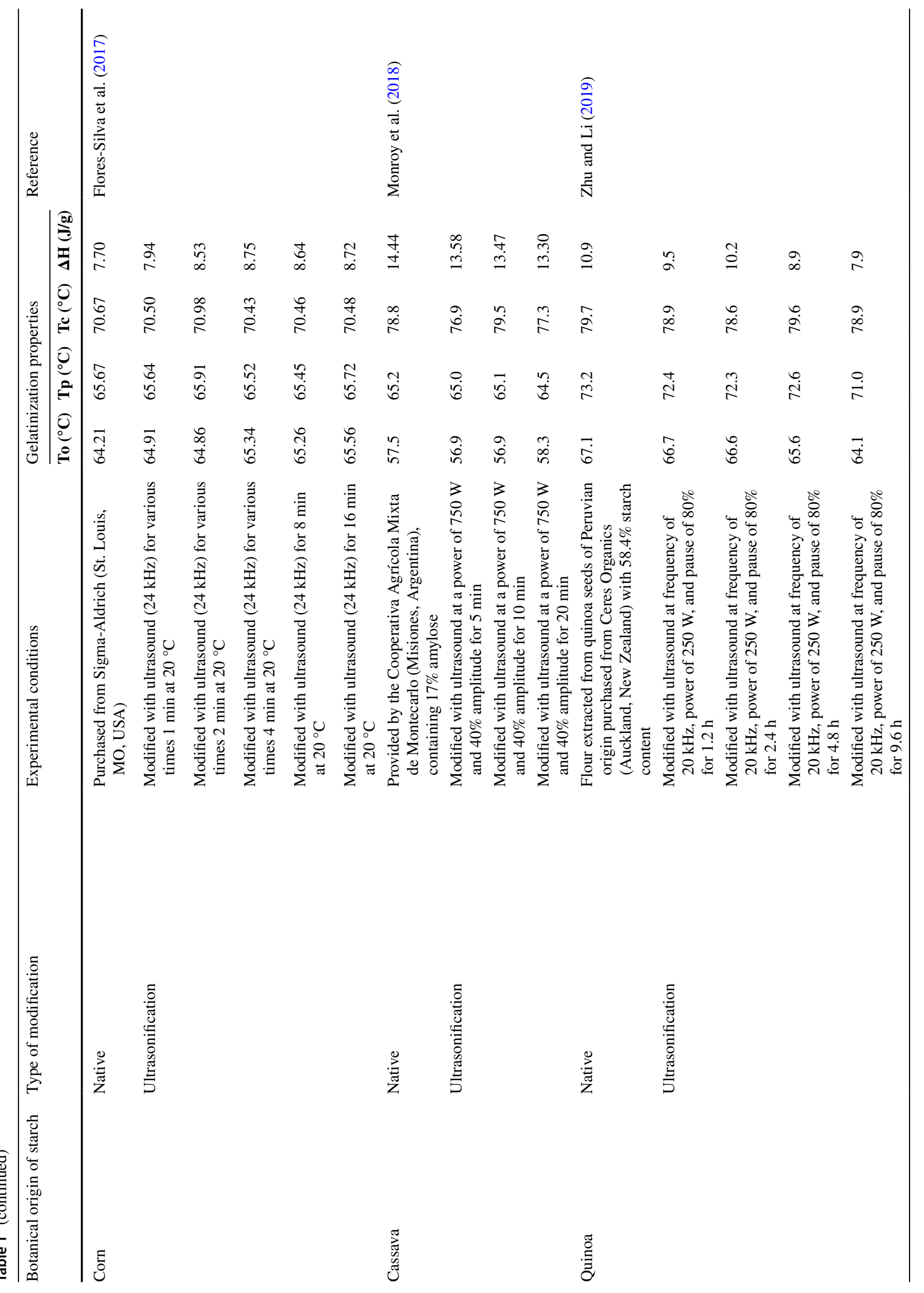




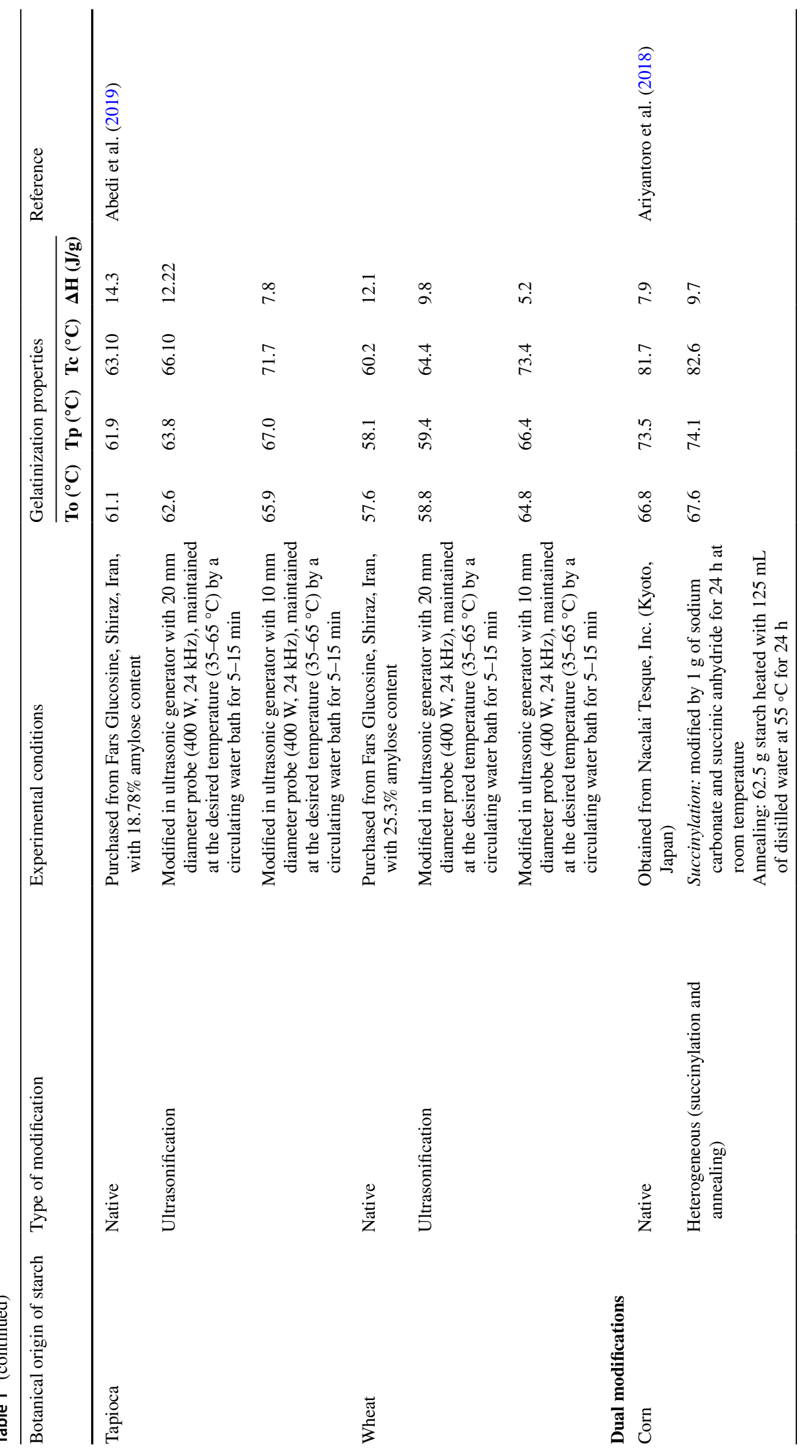




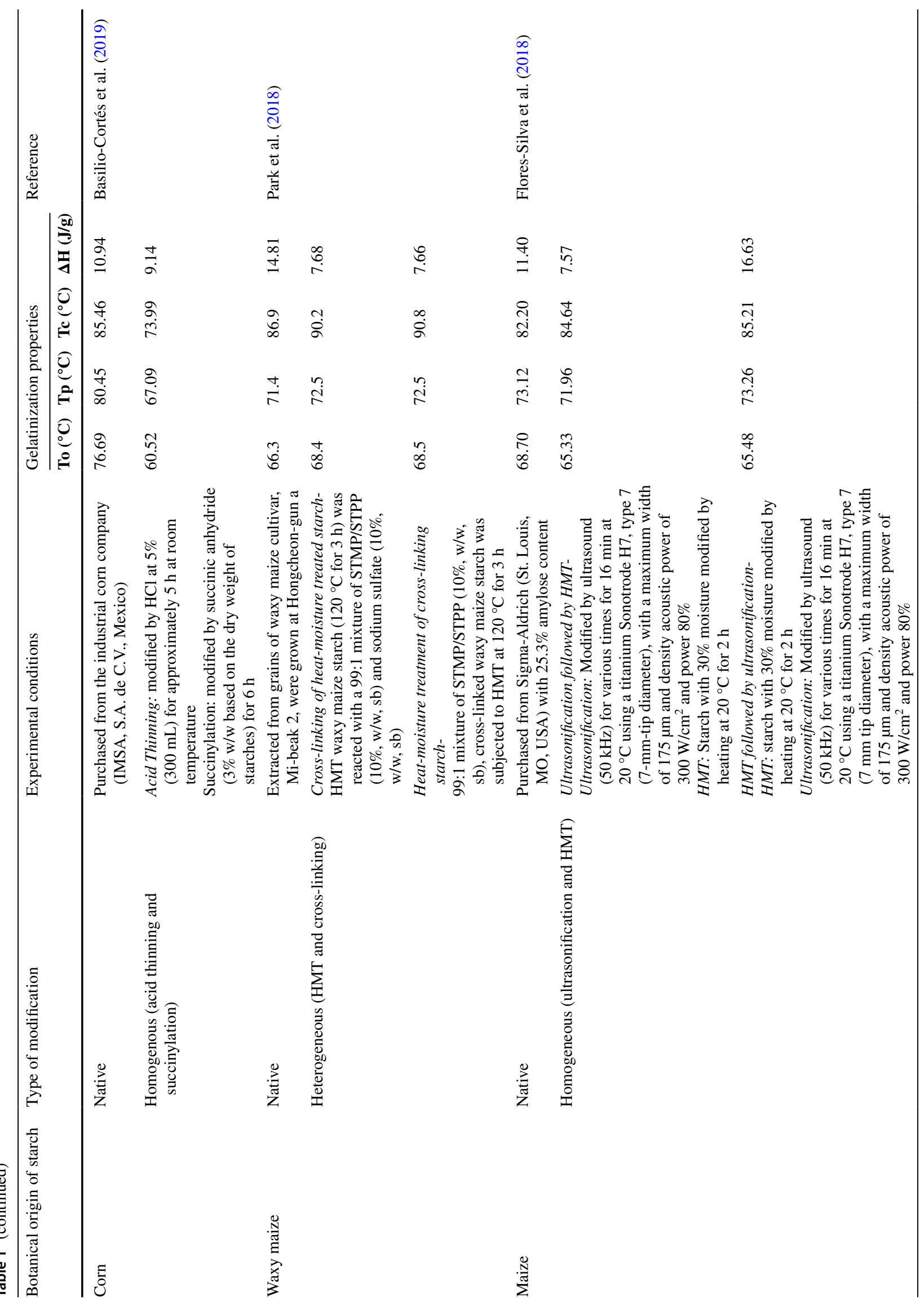


the interference of starch-water interactions during gelatinization due to the presence of protein, therefore showing a significant increase in gelatinization temperature and drop in $\Delta H$ (Yang et al., 2019a, b). Starch and protein from cereals, meat, and other sources play key roles in providing the appropriate textural and rheological characteristics in food items (Jamilah et al., 2009).

\section{Starch Modification}

To procure appropriate for use in food industries, native starches undergo chemical, physical, or dual modification to get the desired properties such as adhesion, texture, heat tolerance, and solubility. These chemical and physical modifications also affect the gelatinization properties of starch which are discussed in detail in the following section.

\section{Chemical Modification}

Chemical modification includes introducing a new functional group into the already existing native starch molecule that results in distinctive changes in its physicochemical properties. Chemical modifications affect characteristics like proximate composition, gelatinization temperature, retrogradation, and pasting characteristics of native starch granules. Major types of chemical modifications used in the food industries include the following.

\section{Acid-Hydrolyzed (Thinned) Starches}

Acid-hydrolyzed (thinned) starches are obtained by treatment of starch with mineral acids such as hydrochloric or sulfuric acids resulting in depolymerization of the starch polymer. (de Siqueira et al., 2017). Acid modification is performed to improve the physicochemical properties of starch and eliminate fatty substances associated with native starches. Acid-treated starches exhibit many desired properties such as increased $\Delta H$, reduced tendency to be retrograded and swelling power, and broadened range of gelatinization temperature as well as loss in pasting viscosities (Pratiwi et al., 2018). The acid treatment initially affects the amorphous domain of the starch granule which is more susceptible followed by slowly moving towards the crystalline domain of the starch granule. Acid hydrolysis leads to an increase in short amylose chains and favors the retrogradation of starch that leads to resistant starch formation. Acid affects hydrolysis amorphous domains followed by slow degradation of crystalline regions leading to an increase in the peak gelatinization temperature $\left(T_{p}\right)$. In a recent study, native and hydrochloric acid-modified (0.1 and $0.5 \mathrm{~mol} \mathrm{~L}^{-1}$ ) pine seed starch was studied using DSC 
and it was concluded that higher acid concentrations promoted crystallinity reduction and loss in the internal structure of the starch granule. However, the gelatinization behavior varied between different genetic varieties (de Siqueira et al., 2019). Another study reported that there is an approximately three-fold reduction in the $\Delta H$ of granules, indicating a weakening of granules postacid hydrolysis modification (Mehfooz et al., 2019). Figure 2A depicts the DSC endotherm of acid-hydrolyzed tapioca starch. Acid-thinned starches are widely used in the manufacture of gelled sweets like gum candies and baked goods. Acid hydrolysis also reduces the tolerance of starches to refrigeration, storage $\left(5^{\circ} \mathrm{C}\right)$, and freeze-thaw cycles (Thys et al., 2013; Ulbrich \& Flöter, 2019). To summarize, acid thinning lowers the peak gelatinization temperature of starch and increases the solubility. This is also accompanied by loss of swelling capacity and viscosity.

\section{Acetylation of Starch}

During acetylation, the acetyl group replaces the $-\mathrm{OH}$ groups of glucose molecules using acetic anhydride and catalysts such as sodium hydroxide. During the acetylation process, the hydroxyl groups $(-\mathrm{OH})$ of glucose monomers are converted into $\mathrm{CH}_{3} \mathrm{COO}$ (acetyl) groups. Hence, acetylation can be considered as esterification of hydroxyl groups that present an anhydroglucose monomer of the starch molecule (Fitch-Vargas et al., 2019). Acetylated starches serve different purposes depending upon the degree of substitution (Colussi et al., 2017). Acetylation increases the solubility of starch in acetone and chloroform in which native starch is sparingly soluble (Abba et al., 2014). Acetylation introduces hydrophilic acetyl groups in the amorphous domain of the starch granules resulting in a decrease of the onset temperature $\left(T_{o}\right)$, suggesting initial disruption of the order in the starch granules with a temperature rise. This decrease indicates the fact
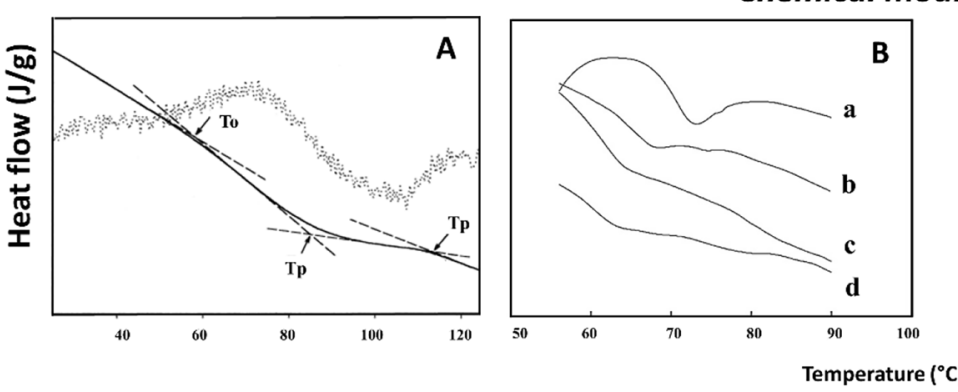

Chemical modifications
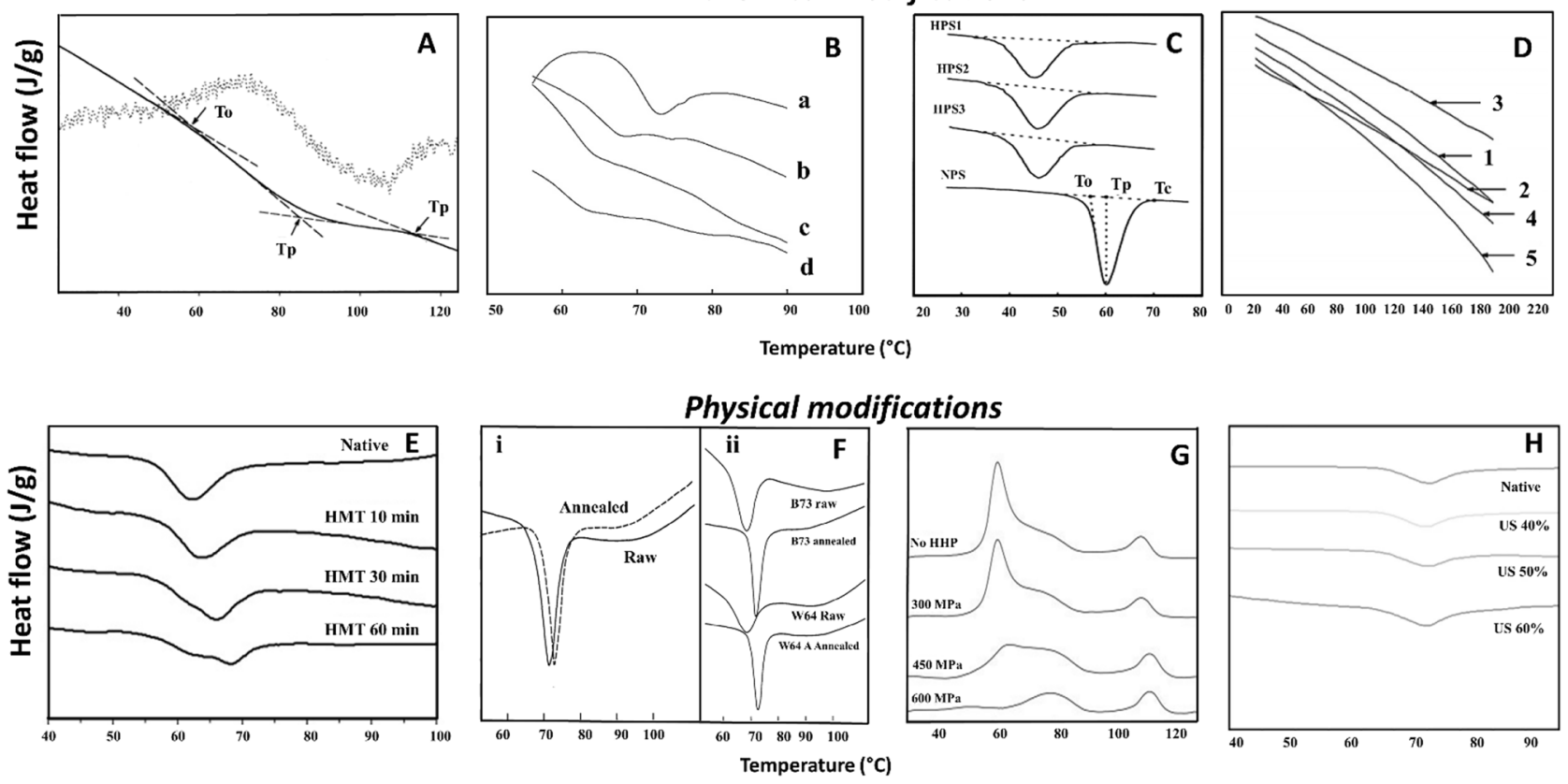

Fig. 2 (A) DSC curve of acid-modified tapioca starch and its derivative for measuring temperature. Figure reproduced from Atichokudomchai et al. (2002) with kind permission from John Wiley and Sons. (B) The DSC curves of native corn starch (a), acetylated corn starches with a degree of substitution (DS) of 0.071 (b), with a DS of 0.105 (c), with a DS of 0.133 (d). Figure reproduced from Han et al. (2012) with kind permission from Elsevier. (C) The heating DSC curves of native and hydroxypropylated phosphate cross-linked potato starch with different degrees of hydroxypropyl substitution and phosphate cross-linking. Figure reproduced from Morikawa et al. (2000) with kind permission from Elsevier. (D) DSC curves of the native starch and the oxidized starches with different degrees of oxidation (1) native starch, (2) oxidized starch $5.9 \%$, (3) oxidized starch $19.5 \%$, (4) oxidized starch $40.5 \%$, and (5) oxidized starch 56.3\%. The figure is reproduced from Zhang et al. (2012) with kind permission from Elsevier. (E) Effect of heat moisture treatment on DSC curves of rice starch for different periods. Figure reproduced from Arns et al. (2015) with kind permission from Elsevier. (F) The DSC spectra (i) exhibit typical endothermic thermogram of commercial starch: raw and annealed, (ii) comparison of raw and annealed starches from two varieties of maize, namely, B73 and W64A starches. Annealing conditions were $50{ }^{\circ} \mathrm{C}$ for $48 \mathrm{~h}$. The figure was reproduced from Krueger et al. (1987) with kind permission from Wiley. (G) DSC thermograms for wheat starch after HHP treatment in $0.1 \mathrm{M} \mathrm{NaCl}(1: 1, \mathrm{w} / \mathrm{w})$ for $15 \mathrm{~min}$ at $257^{\circ} \mathrm{C}$. The image was reproduced from Kweon et al. (2008) with kind permission from Wiley. (H) DSC curves of native and ultrasonically modified (US) purple taro starch. The figure has been reproduced from Martins et al. (2020) with kind permission from Springer 
that the gelatinization of starch is controlled in part by the molecular structure of amylopectin that is affected by any form of chemical modification (Olayinka et al., 2015). While studying the thermal properties of yellow sorghum starch, a similar reduction in $\Delta H$ was observed from 1.7 to $1.61 \mathrm{~J} / \mathrm{g}$ in acetylated starch. The $T_{o}, T_{p}$, and $T_{c}$ values also decrease with an increasing degree of acetylation (Beninca et al., 2008). In another recent study, the effect of acetylation of hulless barley starch on its thermal properties was studied. They have found a declined $T_{p}$ with the increased acetylation. The hydrophilic acetyl groups make the starch more susceptible to water leading to early gelatinization (Chang \& Lv, 2017). A similar trend was also observed while studying the thermal properties of microwave pre-treated acetylated corn starch with different degrees of substitution. With the increasing degree of acetylation, a downward trend in $T_{p}$ and $\Delta H$ was observed. According to the authors, this decrease of $T_{p}$ and $\Delta H$ in microwave-pre-treated acetylated starch was accredited to the destruction of the amorphous regions in starch molecules, hindering the spatial association of starch molecules, thus promoting improved hydration and easy gelatinization compared to native starch (Lin et al., 2019). Figure 2B depicts the decrease in peak areas with an increasing degree of acetylation. The onset temperature $\left(T_{o}\right)$, peak temperature $\left(T_{p}\right)$, and ceasing temperature $\left(T_{c}\right)$ value also decrease with increasing degree of acetylation. In the food industry, they may act as adhesion, thickening, texturizing, film-forming, stabilizing, and binding agents; plentiful applications in are found in the food industry in baked, frozen, and baby foods (Zia-ud-Din et al., 2017). Acetylated starch is stable at low temperatures and resists retrogradation. It also affects the swelling power and freeze-thaw stability of starches (Abba et al., 2014).

\section{Cross-linking of Starch}

Cross-linked starch is obtained by treating native starches using different cross-linking agents like sodium trimetaphosphate (STMP), sodium tripolyphosphate (STPP), epichlorohydrin $(\mathrm{ECH})$, and phosphoryl chloride $\left(\mathrm{POCl}_{3}\right)$. Cross-linking of carboxymethylated starch (CMS) produces hydrogels which can be used in the removal of metal ions from water, as a pharmaceutical gelling agent and emulsion stabilizer, as a tablet disintegrant, or for drug delivery systems (Haq et al., 2019; Wilpiszewska et al., 2019). (Shah et al., 2016). Cross-linking increases resistance to high temperature, high shear, and low $\mathrm{pH}$ and further improves the viscosity and texture of starch. It also restricts the swelling of starch granules under cooking conditions and prevents gelatinization (Ayoub \& Rizvi, 2009). Cross-linking is often used in the food industry to decrease the retrogradation and gelation of amylose in starch. Cross-linking affects other bonds like hydrogen bonds resulting in resistance to higher temperatures, lower $\mathrm{pH}$, and higher shear compared to native starch. Cross-linked starches exhibit biphasic endotherms with a relatively narrow endotherm compared to native samples. Gelatinization temperatures were found to be significantly increased with increasing degrees of crosslinking. The introduction of cross-linking agents such as phosphate groups strengthens the molecular organization of the starch molecules, thus inhibiting gelatinization and increasing $T_{p}$. In a study, the thermal characteristics of glutaraldehyde-cross-linked corn starch were studied using DSC in both acidic and alkaline mediums. $T_{p}$ of cross-linked starches in the acidic medium increased while $\Delta H$ decreased substantially. However, in alkaline medium, both $T_{p}$ and $\Delta H$ decreased compared to the native starch (Gonenc \& Us, 2019). In another study conducted on faba bean and field pea, and corn starch was cross-linked using three methods: phosphoryl chloride ( $\mathrm{POCl}_{3}$-aqueous), sodium trimetaphosphate/sodium tripolyphosphate (STMP/STPP) (STMP-semidry), and STMP/ STPP (STMP-aqueous). Corn starch exhibited the highest $T_{o}, T_{p}$, and $T_{c}$ compared to faba bean and field pea starch, owing to its characteristic compact crystal arrangement of A-type crystalline cereal starch, compared to C-type crystalline pulse starches. The unique C-type starch crystal structure consists of both A- and B-type polymorphs (Guo et al., 2017). Gelatinization in C type starch granules initiates from B-type polymorphs at the central hilum at a lower temperature due to loose packing and then moves to A-type polymorphs. The lower $T_{o}, T_{p}$, and $T_{c}$ for native starches indicate low amylopectin contents. Cross-linking increased $T_{o}, T_{p}, T_{c}$, and $\Delta H$, but the extent of increase in $T_{o}, T_{p}$, and $T_{c}$ varied with the technique of cross-linking and type of starch. The influence of STMP-semidry on thermal stability was more pronounced in faba bean and field pea starch, while the $T_{p}$ of corn starch was more influenced more by the $\mathrm{POCl}_{3}$-aqueous method (Dong \& Vasanthan, 2020). A study reported that the gelatinization properties of different hydroxy propylated phosphate cross-linked potato starch (HPS) by heating and classified as HSP1, HSP2, and HSP3 based on the degree of hydroxypropyl substitution and phosphate cross-linking. It was observed that the $T_{p}$ of HPS1, 2, and 3 were about $15{ }^{\circ} \mathrm{C}$ lower than that of the native potato starch, but the $\Delta H$ did not differ between the three HPS samples. This decrease was due to an increasing degree of hydroxypropylation as the phosphate cross-linking content was almost equal in all three cases (Morikawa \& Nishinari, 2000). This is depicted in Fig. 2C. Cross-linked starches are extensively used in the food industry as thickeners and stabilizers and to improve food textures as well as freeze-thaw stability of starch. 


\section{Oxidization of Starches}

Oxidized starches are obtained by treating them with oxidizing agents such as sodium hypochlorite or hydrogen peroxide, or potassium permanganate. The hydroxyl groups of starch can be subjected to a wide number of reactions for modification like oxidation. The oxidizing agents react with the free hydroxyl group in the monomer (glucose) which results in a carbonyl or carboxyl group. Oxidation of starch results also in the depolymerization of starch molecules by breaking the glycosidic linkages (Moreno et al., 2017). The use of oxidized starch as food additives is increasing in the food industry due to its low viscosity, high stability, and binding properties (Zhang et al., 2012). Oxidation of starch also leads to increased relative crystallinity compared to its native counterpart and shows an increase in gelatinization temperature. It was reported that oxidized white sorghum starch substantially increased the $T_{o}, T_{p}$, and $T_{c}$ (Mehfooz et al., 2019). In another recent study, the thermal properties of vacuum-assisted oxidized corn, cassava, and canna starches were studied. The $\Delta H$ of native starches were the highest followed by oxidized and vacuum-oxidized starches, respectively. This indicated that oxidation partially degrades the crystalline region of the starch granule, and therefore, less energy was required for gelatinization. Vacuum-oxidized corn and canna starches exhibited lower $T_{o}, T_{p}$, and $T_{c}$ compared to their native counterparts. This reduction was explained by the weakening of starch granules, resulting in the destruction of amylopectin in the crystalline region. However, vacuumoxidized cassava starch revealed an opposite trend with an increase in $T_{o}, T_{p}$, and $T_{c}$ compared to its native form. This was explained by depolymerization in the amorphous region of the starch granule and subsequently in the destruction of their destabilizing effect on the crystalline regions, thus resulting in a rise of $T_{o}, T_{p}$, and $T_{c}$ (Zhang et al., 2018). Figure 2D depicts DSC thermograms of oxidized starches. The oxidized starch is used in the food industry for its exceptional functional properties such as low viscosity, high stability, clarity, film-forming, and binding properties. Oxidized starch is often used for coating, sealing, batter binding, emulsification, and dough conditioning in baking (Matsuguma et al., 2009).

\section{Physical Modification}

Physical modification of starch includes alcoholic-alkaline and drum drying methods. These are novel methods for the physical modification of starch. Physically modified starch alters the starch properties including morphology, and functional properties like swelling capacity, water absorption, pasting, and gelatinization, influenced by factors such as temperature, moisture, and pressure. Pre-gelatinization, heat moisture treatment (HMT), and annealing (ANN) are common methods that have found wide applications in the food industry ( $\mathrm{Lv}$ et al., 2018; Yan \& Zhengbiao, 2010). Commonly used physical modifications techniques are-

\section{Pre/Partially Gelatinized Starches}

They are pre-cooked starches that are dried using a drum (drum drying) to form a stable suspension that can be dispersed in cold water. Drum drying is an extensively popular method to modify the starch to obtain improved textures and porous structures for better functional properties in different types of industry. For example, partially gelatinized corn starch exhibited peak gelatinization between $64-72{ }^{\circ} \mathrm{C}$ which is higher compared to the native starch. According to a study conducted by Li et al. (2020), the addition of pre-gelatinized starch increased the viscosity and improved the texture of a gluten-free dough ( $\mathrm{Li}$ et al., 2020).

However, a decrease in $\Delta H$ was observed when compared to native starch (from $12.97 \pm 0.28$ to $0.51 \pm 0.08 \mathrm{~J} / \mathrm{g}$ ) ( Fu et al., 2012). A study was conducted to reveal the effect of partial gelatinization on the physicochemical properties of corn, waxy corn, and wheat starch. The partially gelatinized starches exhibit less $\Delta H$ compared to their native counterparts. For native corn, wheat, and waxy corn starch, the $T_{o}$ increase from 65.5 to $80.3^{\circ} \mathrm{C}$, from 58.1 to $77.9^{\circ} \mathrm{C}$, and from 64.3 to $77.4{ }^{\circ} \mathrm{C}$, respectively. Further, the $T_{o}$ is also found to increase from 70.6 to $83.9{ }^{\circ} \mathrm{C}$, from 62.4 to $81.6^{\circ} \mathrm{C}$, and from 69.9 to $81.6^{\circ} \mathrm{C}$, respectively, for corn, wheat, and waxy corn starch. The rise in gelatinization temperature indicates the degree of reorganization during partial gelatinization (Hickman et al., 2009). These are widely used in the food industry, as a thickening agent. Pregelatinized starch is used extensively in products such as instant food items for infants, confectionaries, and soups. Pre-gelatinized starch swells rapidly in cold water and resulting in improved viscosity and texture of starch-based food products (Vanier et al., 2019).

\section{Hydrothermal Modification of Starch}

Heat-moisture treatment (HMT) and annealing are types of physical modifications involving the heating of starch above glass transition temperatures along with water. Annealing differs from HMT in terms of water content used. Annealing occurs with excess water, whereas the heat-moisture treatment requires less than $35 \%$ water. Hydrothermal treatments affect the functional properties of starch which results in better application in starch-based food products (Kaur \& Singh, 2019; Schafranski et al., 2021). The hydrothermal 
treatment during the gelatinization process especially in the food processing industries is known to cause disorientation of the starch granular organization (Wang et al., 2016). HMT results in a decrease in onset temperature and an increase in $T_{p}$ due to the strengthening of intramolecular bonds promoted by the HMT indicating better thermal stability (Singh et al., 2005). High temperature during HMT increases the mobility of double helixes that form the crystal structure, leading to breakage of hydrogen bonds decreasing in the $\Delta H$ of hydrothermally treated starches when compared to that of native starches (Arns et al., 2015). Figure 2E depicts the effect of HMT on the thermal properties of rice starch. Annealing like HMT increases the onset and peak gelatinization temperature and decreases the $\Delta H$ as well as the gelatinization temperature range of starch. Figure 2F exhibits gelatinization endotherms of annealed starch. These changes during annealing are accredited to the structural transformation of the crystalline domain into amorphous domains, providing increased thermodynamic stability and increased peak gelatinization temperature. The decrease in enthalpy with annealing or HMT of starch implies that the molecular order of the treated starch granules had increased. Annealing of starch thus increases granule structure stability and structural transformations of crystalline domains into amorphous domains. Recent studies were conducted on a new source of starch obtained from Kithul palm (Caryota urens) and observed that the gelatinization parameters $\left(T_{o}, T_{p}\right.$, and $\left.T_{c}\right)$ of Kithul starch are higher than that of sago and corn. The Kithul starch was subjected to dual chemical modification (oxidation and acetylation), and physical modification like annealing. DSC analysis showed that modified forms of Kithul starch exhibited an increase in gelatinization temperatures compared to native starch (Sudheesh et al., 2019a, b). This change depends on crystalline perfection, and the interaction between new functional groups presenting hydroxyl groups in starch granules. An increase in $T_{o}, T_{p}$, and $T_{c}$ was observed in annealed starch. This rise is credited to an escalation in the interaction between amylose-amylose, and amylose-amylopectin chains. HMT starch exhibits greater thermal stability and shear resistance and is hence used in food products like confectionaries, sauces, soups noodles, and pasta. Recent studies have explored the use of HMT starch in food items like pasta and noodles to obtain desirable qualities like good expansion, minimum cooking time, and good tensile strength (Chandla et al., 2017; Kaur \& Singh, 2019; Liao et al., 2019; Schafranski et al., 2021). Annealing is a lucrative and simple technique used to modify the functional properties of starch to develop several food products. Annealed starches are used majorly as viscosity modifiers, glazing agents, fat replacers, emulsion agents, encapsulation material, and bulking agents (Schmiele et al., 2018).

\section{Non-Thermal Physical Modification of Starch}

Food items are preserved by exposing them to high temperatures for a short period. These treatments result in the loss of essential nutrients, and flavors. These problems can be solved by non-thermal technology. Non-thermal treatments preserve the important characteristics of food including texture, color, nutrients, and taste as compared to the traditional thermal processes (Zhang et al., 2019a, b, c). Some of the non-thermal methods use ultrasound effects, high hydrostatic pressure, and microwave treatments for the modification of starches. Some established applications of ultrasound in food processing consist of homogenization, defoaming, filtration, extraction, emulsification, crystallization, and extrusion (Jambrak et al., 2010). High hydrostatic pressure has been effectively used to prolong the shelf life of food products with the least impact on their taste, nutrition, and aroma (Huang et al., 2017). Effects of high hydrostatic pressure $(100,300$, and $500 \mathrm{MPa}$ for 15 and $30 \mathrm{~min}$ at $25^{\circ} \mathrm{C}$ ) on thermal properties of maize, potato, and sweet potato starches $(20 \%$, w/w) were investigated by Rahman et al. (2020). It was observed that the effect of high hydrostatic pressure on starch is a function of molecular structure. Sweet potato starch with a complex molecular structure is not affected by high hydrostatic pressure compared to maize and potato starch which show an increase in gelatinization temperature (Rahman et al., 2020). Figure 2 G exhibits DSC parameters of high hydrostatic pressure treated starch.

Microwaves are electromagnetic radiations in the frequency range of $300 \mathrm{MHz}-300 \mathrm{GHz}$. The microwaves generate heat inside the starch granules due to alternating electromagnetic fields at high frequencies. Other advantages of microwave treatment involve faster and selective heating, energy efficiency, and control of the treatment process (Colman et al., 2014). A study conducted by Colman et al. (2014) showed that starch exposed to microwave exhibits an increase in gelatinization temperature. Ultrasonic treatment requires a shorter time and provides better yield compared to traditional food processing techniques. According to Jambrak et al. (2010), ultrasonicated corn starch did not show a statistical increase in the gelatinization temperature compared to native corn starch $\left(74.99^{\circ} \mathrm{C}\right)$. Lower $T_{p}$ and less $\Delta H(8.733 \mathrm{~kJ} / \mathrm{kg})$ for corn starch suspensions were sonicated for $15 \mathrm{~min}$ and was observed compared to the untreated corn starch (Jambrak et al., 2010). Ultrasonicated starch is shown to increase the pore size of starch granules, easing the release of flavoring agents and spices (Sujka, 2017). Figure 2H shows the gelatinization parameters of ultrasonicated starch. A study was conducted to investigate rice starch modified by a combined ultrasonic-microwave technique. The treatment exhibited substantial changes in important functional properties including gel firmness, degree of hydrolysis, and retrogradation of starch (Brasoveanu \& Nemtanu, 2014). 


\section{Dual Modification}

Dual modification of starch combines two methods-either chemical and physical modifications or chemical and enzymatic methods. A combination of two chemical modifications is the most common. There are two classes of dual modification, namely, homogeneous and heterogeneous dual modifications. The homogeneous dual modification consists of either physical/physical or chemical/chemical dual modification. Heterogeneous dual modifications include a combination of physical and chemical dual modifications (Ashogbon, 2021). Frequently applied dual chemical modifications include acetylation/oxidation or cross-linking/acetylation (Zia-udDin et al., 2017). Heterogeneous dual modification of starch (succinylation-annealing) increases swelling power, water binding capacity, gelatinization temperature, and enthalpy gelatinization. This is highly desirable for food products like sauces, pasta, and noodles that require starch to be heated and shear-stress resistant during processing (Lin et al., 2019). A previous study has suggested that DSC analysis exhibited improved thermal stability and peak gelatinization temperature after dual modification. (Ashogbon, 2021). For example, the Kithul starch was subjected to dual chemical modification (oxidation and acetylation), and physical modification like annealing. DSC analysis showed that modified forms of Kithul starch exhibited an increase in gelatinization temperatures compared to native starch. This change depends on crystalline perfection, and the interaction between new functional groups presenting hydroxyl groups in starch granules (Sudheesh et al., 2019a, b). In another recent study, taro starch was subjected to dual modification by HMT and ultrasonication. The dual-modified samples exhibited reduced $\Delta H$ and increased $T_{p}$. This was accredited to the fact that HMT causes reorganization of starch chains in a more ordered structure which was disturbed by the application of ultrasound. This resulted in easy penetration of water and resulted in less energy for gelatinization (Thomaz et al., 2020). In yet another study conducted, the effect of the dual modification, acid thinning, and succinylation is studied, for possible applications in the food industry. It was observed that there was no extensive difference in the thermal properties of native and modified starch since the treatments only affected the amorphous regions of the starch granules. The $T_{p}$ of native starch was $66.51{ }^{\circ} \mathrm{C}$ whereas the dual modified starch exhibited $T_{p}$ at $65.87^{\circ} \mathrm{C} . \Delta H$ for native starch was $13.67 \mathrm{~J} / \mathrm{g}$ whereas modified starch had $\Delta H$ of $13.80 \mathrm{~J} / \mathrm{g}$ (Cabrera-Canales et al., 2021). A corn starch was exposed to hydrothermal treatments in various orders. The native acorn starch exhibited $T_{o}, T_{p}, T_{c}$, and $\Delta H$ at $59.9,71.3,80.6^{\circ} \mathrm{C}$, and $14.9 \mathrm{~mJ} / \mathrm{mg}$, respectively. The $T_{o}$ of HMT-annealed and HMT starches were comparable but higher than that of annealed starch. It shows that HMT had a greater effect on the crystalline region of starch compared to annealing. However, the $T_{o}$ of annealed-HMT starch and the $T_{p}$ and $T_{c}$ of both dual modified starches were lower than HMT starch but higher than annealed starch. This revealed that the second treatment in each case counteracts the effects of the first treatment (Molavi et al., 2018). In the baking industry, cross-linked starch decreased the crumb firmness of bread. This undesirable property was improved by subjecting the starch to dual modification (cross-linking and acetylation) leading to an increase in bread volume and crumb structure (Lakshmi, 2005). Table 1 compares the gelatinization properties of native and modified starch from recent studies.

\section{Other Techniques for Physicochemical Characterization}

The thermal gelatinization properties of starches may vary depending on various factors including botanical source, amylose to amylopectin ratio, type crystallinity, and conditions of chemical, physical, or dual modification (Table 1). Although DSC is an indispensable tool in understanding the thermal characteristics, it alone cannot represent the overall thermal properties of starch. Often other techniques like thermogravimetric analysis (TGA) and differential thermal analysis (DTA) are inevitable and critical in predicting the overall thermal events of any material including starch. Further, DSC shows other drawbacks including its destructive nature and the dynamic nature of the technique. In addition, it is hard to differentiate the individual changes in gelatinization properties of starch which has undergone overlapping dual modification. Since the pursuit of producing better, cheaper, and healthier starch-based food products never stops, further research and multidisciplinary approaches using various techniques including viscometry, microscopy, spectroscopy, X-ray diffraction, and other methods of thermal analysis are used to investigate the altered physicochemical properties of modified starch used in the food industry which can extend more efficient services to the consumers. Microscopy techniques such as scanning electron microscopy are used to investigate the morphology of modified starch granules. X-ray diffraction measurements are used to analyze if the modifications alter the crystalline structure of starch. Fourier transform infrared spectroscopy is the most widely used technique to study characteristic functional groups. Further, Raman spectroscopy is also applied extensively to study the chemical and structural characteristics of modified starch (Pineda-Gomez et al., 2021). To select modified starch for a particular application, especially the food industry, properties such as structure, chemical composition, organoleptic characteristics, viscosity, shelf stability, and resistance to heat, and low $\mathrm{pH}$ must be considered. Therefore, detailed characterization of modified starch using the techniques is necessary. 


\section{Conclusion}

Since starch forms a major part of our daily diet, gelatinization properties have become an important parameter to be considered while processing or cooking food. Modified starch can be used in all sectors of the food industry including the beverage, canned food, baby food, and sweet industries. Starch modification influences the functional quality, selectivity, and suitability of the modified starch for various nutritional, pharmaceutical, and food industrial formulations. Further, starch modification alters the gelatinization properties to improve and tailor its functional characteristics to specific food applications. DSC analysis is important for elucidating the complicated gelatinization characteristics of starch subjected to various types of modifications used in food industries. Thus, it is important to choose the correct form of modification based on gelatinization properties for the processing of starch in the food industry.

This review suggests that generally physically modified starches including partial/pre-gelatinization, HMT, annealing, and high hydrostatic pressure treatment are widely used in pre-cooked/ready-to-eat meals like soups and sauces since they provide high gelatinization temperatures and better solubility of starch. Similarly, cross-linked and oxidized starches also require a short duration and higher temperature to gelatinize and improve the texture as well as the shelf life of starchbased food products. Other modification methods including acid hydrolysis, acetylation, and ultrasonication reduce the gelatinization temperature of starch, making them appropriate for the manufacture of gelled sweets, sauces, and soups owing to lowered $T_{p}$. However, these modifications also exhibit some disadvantages including lowering firmness of starch gels, reduction in swelling capacity, or viscosity. These disadvantages can be overcome by dual modification. A combination of cross-linked and acetylated starch is useful for the packaged and frozen food industry. While cross-linking increases the gelatinization temperature, cross-linked starch improves the texture and resistance of starch to extremely cold and high temperatures. A wide array of modified starch is yet to be tested for increased thermal stability.

Acknowledgements We thank Manasa G. Shetty, research scholar, Department of Biophysics, Manipal School of Life Sciences (MSLS), Manipal Academy of Higher Education (MAHE), for her cooperation while drawing the schemes in the manuscript. PN thanks MAHE, Manipal, Karnataka, India, for the Dr. T.M.A. Pai Ph.D. fellowship. IC thanks Department of Science and Technology (DST), Govt. of Karnataka, India for Ph.D. fellowship. NM thanks the MSLS, MAHE, Manipal, Karnataka, India, for providing the infrastructure needed.

Funding Open access funding provided by Manipal Academy of Higher Education, Manipal. NM was financially supported by the Department of Biotechnology (DBT) and Department of Science and Technology (DST), Government of India, India (project number: BT/ PR25099/NER/95/1014/2017), and DST (INT/Thai/P-10/2019).
Availability of Data and Materials The data presented in this study are available by request from the corresponding author.

\section{Declarations}

Ethics Approval Not applicable.

Conflict of Interest The authors declare no competing interests.

Open Access This article is licensed under a Creative Commons Attribution 4.0 International License, which permits use, sharing, adaptation, distribution and reproduction in any medium or format, as long as you give appropriate credit to the original author(s) and the source, provide a link to the Creative Commons licence, and indicate if changes were made. The images or other third party material in this article are included in the article's Creative Commons licence, unless indicated otherwise in a credit line to the material. If material is not included in the article's Creative Commons licence and your intended use is not permitted by statutory regulation or exceeds the permitted use, you will need to obtain permission directly from the copyright holder. To view a copy of this licence, visit http://creativecommons.org/licenses/by/4.0/.

\section{References}

Abba, H., Ibrahim, A., Shallangwa, G. A., Uba, S., \& Dallatu, Y. A. (2014). Effect of acetylation on stability to retrogradation of starch extracted from wild Polynesian arrowroot (Tacca leontopetaloides (L.) Kuntze) for utilization as adhesive on paper. Journal of Polymers, 2014, 1-9. https://doi.org/10.1155/2014/732174

Abbas, K. A., Khalil, K. S., \& Meor Hussin, A. S. (2010). Modified starches and their usages in selected food products: A review study. Journal of Agricultural Science, 2(2), 90-100. https://doi. org/10.5539/jas.v2n2p90

Abedi, E., Pourmohammadi, K., Jahromi, M., Niakousari, M., \& Torri, L. (2019). The effect of ultrasonic probe size for effective ultrasoundassisted pregelatinized starch. Food and Bioprocess Technology, 12(11), 1852-1862. https://doi.org/10.1007/s11947-019-02347-2

Alcázar-Alay, S. C., \& Meireles, M. A. A. (2015). Physicochemical properties, modifications and applications of starches from different botanical sources. Food Science and Technology, 35(2), 215-236. https://doi.org/10.1590/1678-457X.6749

Ali, N. A., Dash, K. K., \& Routray, W. (2020). Physicochemical characterization of modified lotus seed starch obtained through acid and heat moisture treatment. Food Chemistry, 319(February), 126513. https://doi.org/10.1016/j.foodchem.2020.126513

Alimi, B. A., \& Workneh, T. S. (2018). Structural and physicochemical properties of heat moisture treated and citric acid modified acha and iburu starches. Food Hydrocolloids, 81, 449-455. https://doi. org/10.1016/j.foodhyd.2018.03.027

Alvani, K., Qi, X., Tester, R. F., \& Snape, C. E. (2011). Physicochemical properties of potato starches. Food Chemistry, 125(3), 958-965. https://doi.org/10.1016/j.foodchem.2010.09.088

Ariyantoro, A. R., Katsuno, N., \& Nishizu, T. (2018). Effects of dual modification with succinylation and annealing on physicochemical, thermal and morphological properties of corn starch. Foods, 7(9). https://doi.org/10.3390/foods7090133

Arns, B., Bartz, J., Radunz, M., do Evangelho, J. A., Pinto, V. Z., da Zavareze, E. R., \& Dias, A. R. G. (2015). Impact of heat-moisture treatment on rice starch, applied directly in grain paddy rice or in isolated starch. LWT - Food Science and Technology, 60(2), 708-713. https://doi.org/10.1016/j.1wt.2014.10.059 
Ashogbon, A. O. (2021). Dual modification of various starches: Synthesis, properties and applications. Food Chemistry, 342, 128325. https://doi.org/10.1016/j.foodchem.2020.128325

Atichokudomchai, N., Varavinit, S., \& Chinachoti, P. (2002). Gelatinization transitions of acidmodified tapioca starches by differential scanning calorimetry (DSC). Starch/staerke, 54(7), 296-302. https://doi.org/10.1002/1521-379X(200207)54:73.0.CO;2-

Ayoub, A. S., \& Rizvi, S. S. H. (2009). An overview on the technology of cross-linking of starch for nonfood applications. Journal of Plastic Film and Sheeting, 25(1), 25-45. https://doi.org/10. 1177/8756087909336493

Basilio-Cortés, U. A., González-Cruz, L., Velazquez, G., TenienteMartínez, G., Gómez-Aldapa, C. A., Castro-Rosas, J., \& BernardinoNicanor, A. (2019). Effect of dual modification on the spectroscopic, calorimetric, viscosimetric and morphological characteristics of corn starch. Polymers, 11(2). https://doi.org/10.3390/polym11020333

Bauer, B. A., \& Knorr, D. (2005). The impact of pressure, temperature and treatment time on starches: Pressure-induced starch gelatinisation as pressure time temperature indicator for high hydrostatic pressure processing. Journal of Food Engineering, 68(3), 329-334. https://doi.org/10.1016/j.jfoodeng.2004.06.007

Beninca, C., Demiate, I. M., Lacerda, L. G., Filho, M. A. S. C., Ionashiro, M., \& Schnitzler, E. (2008). Thermal behavior of corn starch granules modified by acid treatment at 30 and $50^{\circ} \mathrm{C}$. Ecletica Quimica, 33(3), 13-18.

Biduski, B., da Silva, F. T., da Silva, W. M., de Halal, S. L., El, M., Pinto, V. Z., Dias, A. R. G., da Zavareze, E., \& R. (2017). Impact of acid and oxidative modifications, single or dual, of sorghum starch on biodegradable films. Food Chemistry, 214, 53-60. https://doi.org/ 10.1016/j.foodchem.2016.07.039

Brasoveanu, M., \& Nemtanu, M. R. (2014). Behaviour of starch exposed to microwave radiation treatment. Starch/staerke, 66(12), 3-14. https://doi.org/10.1002/star.201200191

Cabrera-Canales, Z. E., Velazquez, G., Rodríguez-Marín, M. L., Méndez-Montealvo, G., Hernández-Ávila, J., Morales-Sánchez, E., \& Gómez-Aldapa, C. A. (2021). Dual modification of achira (Canna indica L) starch and the effect on its physicochemical properties for possible food applications. Journal of Food Science and Technology, 58(3), 952-961. https://doi.org/10.1007/ s13197-020-04609-w

Chandla, N. K., Saxena, D. C., \& Singh, S. (2017). Processing and evaluation of heat moisture treated (HMT) amaranth starch noodles; An inclusive comparison with corn starch noodles. Journal of Cereal Science, 75, 306-313. https://doi.org/10.1016/j. jcs.2017.05.003

Chang, Y., \& Lv, Y. (2017). Structure, functionality, and digestibility of acetylated hulless barley starch. International Journal of Food Properties, 20(8), 1818-1828. https://doi.org/10.1080/10942912. 2016.1220013

Chen, Y., She, Y., Zhang, R., Wang, J., Zhang, X., \& Gou, X. (2020). Use of starch-based fat replacers in foods as a strategy to reduce dietary intake of fat and risk of metabolic diseases. Food Science \& Nutrition, 8(1), 16-22.

Colman, T. A. D., Demiate, I. M., \& Schnitzler, E. (2014). The effect of microwave radiation on some thermal, rheological and structural properties of cassava starch. Journal of Thermal Analysis and Calorimetry, 115(3), 2245-2252. https://doi.org/10.1007/ s10973-012-2866-5

Colussi, R., Kringel, D., Kaur, L., da Rosa Zavareze, E., Dias, A. R. G., \& Singh, J. (2020). Dual modification of potato starch: Effects of heat-moisture and high pressure treatments on starch structure and functionalities. Food Chemistry, 318(January). https://doi. org/10.1016/j.foodchem.2020.126475

Colussi, R., Pinto, V. Z., El Halal, S. L. M., Biduski, B., Prietto, L., Castilhos, D. D., et al. (2017). Acetylated rice starches films with different levels of amylose: Mechanical, water vapor barrier, thermal, and biodegradability properties. Food Chemistry, 221, 1614-1620. https://doi.org/10.1016/j.foodchem.2016.10.129

Dai, L., Zhang, J., \& Cheng, F. (2020). Cross-linked starch-based edible coating reinforced by starch nanocrystals and its preservation effect on graded Huangguan pears. Food Chemistry, 311, 125891. https://doi.org/10.1016/j.foodchem.2019.125891

de Siqueira, G. L. D. A., Hornung, P. S., da Silveira, A. C., da Silveira Lazzarotto, S. R., do Prado Cordoba, L., Schnitzler, E., \& Lazzarotto, M. (2017). Impact of treatment with HCL/alcoholic in the modification of corn starch. Journal of Thermal Analysis and Calorimetry, 129(3), 1705-1713. https://doi.org/10.1007/s10973-017-6299-z

de Siqueira, G. L. D. A., da Silveira, A. C., da Silveria Lazzarotto, S. R., de Godoy, R. C. B., Schnitzler, E., \& Lazzarotto, M. (2019). Hydrolysis of the low gelatinization temperature Araucaria angustifolia pine seed starch: Thermal, rheological and structural properties. Journal of Thermal Analysis and Calorimetry, 138(2), 1269-1278. https://doi.org/10.1007/s10973-019-08180-1

Depree, J. A., \& Savage, G. P. (2001). Physical and flavour stability of mayonnaise. Trends in Food Science \& Technology, 12(5-6), 157-163.

Dong, H., \& Vasanthan, T. (2020). Effect of phosphorylation techniques on structural, thermal, and pasting properties of pulse starches in comparison with corn starch. Food Hydrocolloids, 109, 106078. https://doi.org/10.1016/j.foodhyd.2020.106078

Du, J., Yang, Z., Xu, X., Wang, X., \& Du, X. (2019). Effects of tea polyphenols on the structural and physicochemical properties of high-hydrostatic-pressure-gelatinized rice starch. Food Hydrocolloids, 91(130), 256-262. https://doi.org/10.1016/j.foodhyd. 2019.01 .035

Fan, Y., \& Picchioni, F. (2020). Modification of starch: A review on the application of "green" solvents and controlled functionalization. Carbohydrate Polymers, 241, 116350.

Fitch-Vargas, P. R., Camacho-Hernández, I. L., Martínez-Bustos, F., Islas-Rubio, A. R., Carrillo-Cañedo, K. I., Calderón-Castro, A., et al. (2019). Mechanical, physical and microstructural properties of acetylated starch-based biocomposites reinforced with acetylated sugarcane fiber. Carbohydrate Polymers, 219, 378-386. https://doi.org/10.1016/j.carbpol.2019.05.043

Flores-Silva P. C, Roldan-Cruz C. A., Chavez-Esquivel, G., Vernon Carter, E. J., Bello-Perez, L. A., \& Alvarez-Ram J. (2017). In vitro digestibility of ultrasound-treated corn starch. SciFed Journal of Immunology, 1(1), 1-25. https://doi.org/10.23959/sfji-1000006

Flores-Silva, P. C., Alvarez-Ramirez, J., \& Bello-Perez, L. A. (2018). Effect of dual modification order with ultrasound and hydrothermal treatments on starch digestibility. Starch - Stärke, 70(5-6), 1700284. https://doi.org/10.1002/star.201700284

Fu, Z. Q., Wang, L. J., Li, D., \& Adhikari, B. (2012). Effects of partial gelatinization on structure and thermal properties of corn starch after spray drying. Carbohydrate Polymers, 88(4), 1319-1325. https://doi.org/10.1016/j.carbpol.2012.02.010

Gonenc, I., \& Us, F. (2019). Effect of glutaraldehyde crosslinking on degree of substitution, thermal, structural, and physicochemical properties of corn starch. Starch/Staerke, 71(3-4). https://doi. org/10.1002/star.201800046

Govindaraju, I., Chakraborty, I., Baruah, V. J., Sarmah, B., Mahato, K. K., \& Mazumder, N. (2020). Structure and morphological properties of starch macromolecule using biophysical techniques. Starch/staerke. https://doi.org/10.1002/star.202000030

Govindaraju, I., Zhuo, G.-Y., Chakraborty, I., Melanthota, S. K., Mal, S. S., Sarmah, B., et al. (2021). Investigation of structural and physico-chemical properties of rice starch with varied amylose content: A combined microscopy, spectroscopy, and thermal study. Food Hydrocolloids, 107093. https://doi.org/10.1016/j. foodhyd.2021.107093

Guo, Z., Jia, X., Zhao, B., Zeng, S., Xiao, J., \& Zheng, B. (2017). C-type starches and their derivatives: Structure and function. 
Annals of the New York Academy of Sciences, 1398(1), 47-61. https://doi.org/10.1111/nyas.13351

Han, F., Liu, M., Gong, H., Lü, S., Ni, B., \& Zhang, B. (2012). Synthesis, characterization and functional properties of low substituted acetylated corn starch. International Journal of Biological Macromolecules, 50(4), 1026-1034. https://doi.org/10.1016/j. ijbiomac.2012.02.030

Haq, F., Yu, H., Wang, L., Teng, L., Haroon, M., Khan, R. U., et al. (2019). Advances in chemical modifications of starches and their applications. Carbohydrate Research, 476(February), 12-35. https://doi.org/10.1016/j.carres.2019.02.007

Hickman, B. E., Janaswamy, N. S., \& Yao, Y. (2009). Properties of starch subjected to partial gelatinization and $\beta$-amylolysis. Journal of Agricultural and Food Chemistry, 57(2), 666-674. https:// doi.org/10.1021/jf8030698

Hong, J., An, D., Li, L., Liu, C., Li, M., Buckow, R., et al. (2020). Structural, rheological and gelatinization properties of wheat starch granules separated from different noodle-making process. Journal of Cereal Science, 91(August 2019). https://doi.org/10. 1016/j.jcs.2019.102897

Hu, W. X., Chen, J., Xu, F., Chen, L., \& Zhao, J. W. (2020). Study on crystalline, gelatinization and rheological properties of japonica rice flour as affected by starch fine structure. International Journal of Biological Macromolecules, 148, 1232-1241. https://doi. org/10.1016/j.ijbiomac.2019.11.020

Hu, X. P., Zhang, B., Jin, Z. Y., Xu, X. M., \& Chen, H. Q. (2017). Effect of high hydrostatic pressure and retrogradation treatments on structural and physicochemical properties of waxy wheat starch. Food Chemistry, 232, 560-565. https://doi.org/10.1016/j. foodchem.2017.04.040

Huang, H. W., Wu, S. J., Lu, J. K., Shyu, Y. T., \& Wang, C. Y. (2017). Current status and future trends of high-pressure processing in food industry. Food Control, 72(12), 1-8. https://doi.org/10. 1016/j.foodcont.2016.07.019

Jackson, D. S., \& Ratnayake, W. A. (2006). Gelatinization and solubility of corn starch during heating in excess water : New insights. Journal of Agricultural and Food Chemistry, 54(1), 3712-3716.

Jambrak, A. R., Herceg, Z., Šubarić, D., Babić, J., Brnčić, M., Brnčić, S. R., et al. (2010). Ultrasound effect on physical properties of corn starch. Carbohydrate Polymers, 79(1), 91-100. https://doi. org/10.1016/j.carbpol.2009.07.051

Jamilah, B., Mohamed, A., Abbas, K. A., Abdul Rahman, R., Karim, P., \& Hashim, D. M. (2009). Protein-starch interaction and their effect on thermal and rheological characteristics of a food system: A review. Journal of Food, Agriculture, \& Environment, 7, 169-174.

Javadian, N., Mohammadi Nafchi, A., \& Bolandi, M. (2021). The effects of dual modification on functional, microstructural, and thermal properties of tapioca starch. Food Science \& Nutrition, 9, 5467-5476. https://doi.org/10.1002/fsn3.2506

Kaur, M., \& Singh, S. (2019). Influence of heat-moisture treatment (HMT) on physicochemical and functional properties of starches from different Indian oat (Avena sativa L.) cultivars. International Journal of Biological Macromolecules, 122, 312-319. https://doi.org/10.1016/j.ijbiomac.2018.10.197

Kim, J. Y., Lee, Y. K., \& Chang, Y. H. (2017). Structure and digestibility properties of resistant rice starch cross-linked with citric acid. International Journal of Food Properties, 20(00), 2166-2177. https://doi.org/10.1080/10942912.2017.1368551

Krueger, B. R., Knutson, C. A., Inglett, G. E., \& Walker, C. E. (1987). A differential scanning calorimetry study on the effect of annealing on gelatinization behavior of corn starch. Journal of Food Science, 52(3), 715-718. https://doi.org/10.1111/j.1365-2621. 1987.tb06709.x

Kweon, M., Slade, L., \& Levine, H. (2008). Effect of sodium chloride on glassy and crystalline melting transitions of wheat starch treated with high hydrostatic pressure: Prediction of solute-induced barostability from nonmonotonic solute-induced thermostability. Starch/staerke, 60(3-4), 127-133. https://doi. org/10.1002/star.200700669

Lakshmi, J. (2005). Bakery and confectionary products. Food Science and Technology (Vol. 1). https://doi.org/10.1016/B978-0-12811449-0/00009-8

Lebenthal-Bendor, Y., Theuer, R. C., Lebenthal, A., Tabi, I., \& Lebenthal, E. (2001). Malabsorption of modified food starch (acetylated distarch phosphate) in normal infants and in 8-24-month-old toddlers with non-specific diarrhea, as influenced by sorbitol and fructose. Acta Paediatrica, 90(12), 1368-1372.

Leite, T. S., de Jesus, A. L. T., Schmiele, M., Tribst, A. A. L., \& Cristianini, M. (2017). High pressure processing (HPP) of pea starch: Effect on the gelatinization properties. LWT - Food Science and Technology, 76, 361-369. https://doi.org/10.1016/j. lwt.2016.07.036

Li, Q., Liu, S., Obadi, M., Jiang, Y., Zhao, F., Jiang, S., \& Xu, B. (2020). The impact of starch degradation induced by pre-gelatinization treatment on the quality of noodles. Food Chemistry, 302, 125267. https://doi.org/10.1016/j.foodchem.2019.125267

Li, Y., Hu, A., Zheng, J., \& Wang, X. (2019). Comparative studies on structure and physiochemical changes of millet starch under microwave and ultrasound at the same power. International Journal of Biological Macromolecules, 141, 76-84. https://doi.org/ 10.1016/j.ijbiomac.2019.08.218

Liao, L., Liu, H., Gan, Z., \& Wu, W. (2019). Structural properties of sweet potato starch and its vermicelli quality as affected by heat-moisture treatment. International Journal of Food Properties, 22(1), 11221133. https://doi.org/10.1080/10942912.2019.1626418

Lin, D., Zhou, W., Yang, Z., Zhong, Y., Xing, B., Wu, Z., et al. (2019). Study on physicochemical properties, digestive properties and application of acetylated starch in noodles. International Journal of Biological Macromolecules, 128, 948-956. https://doi.org/10. 1016/j.ijbiomac.2019.01.176

Liu, J., Zhao, Q., Zhou, L., Cao, Z., Shi, C., \& Cheng, F. (2017). Influence of environmental temperature during grain filling period on granule size distribution of rice starch and its relation to gelatinization properties. Journal of Cereal Science, 76, 42-55. https:// doi.org/10.1016/j.jcs.2017.05.004

Liu, Y., Yu, J., Copeland, L., Wang, S., \& Wang, S. (2019). Gelatinization behavior of starch: Reflecting beyond the endotherm measured by differential scanning calorimetry. Food Chemistry, 284(29), 53-59. https://doi.org/10.1016/j.foodchem.2019.01.095

Lv, Q. Q., Li, G. Y., Xie, Q. T., Zhang, B., Li, X. M., Pan, Y., \& Chen, H. Q. (2018). Evaluation studies on the combined effect of hydrothermal treatment and octenyl succinylation on the physic-chemical, structural and digestibility characteristics of sweet potato starch. Food Chemistry, 256, 413-418. https://doi.org/10.1016/j. foodchem.2018.02.147

Martins, A., Beninca, C., Bet, C. D., Bisinella, R. Z. B., de Oliveira, C. S., Hornung, P. S., \& Schnitzler, E. (2020). Ultrasonic modification of purple taro starch (Colocasia esculenta B. Tini): structural, psychochemical and thermal properties. Journal of Thermal Analysis and Calorimetry, 142(2), 819-828. https://doi. org/10.1007/s10973-020-09298-3

Mathobo, V. M., Silungwe, H., Ramashia, S. E., \& Anyasi, T. A. (2021). Effects of heat-moisture treatment on the thermal, functional properties and composition of cereal, legume and tuber starches-a review. Journal of Food Science and Technology, 58(2), 412-426. https://doi.org/10.1007/s13197-020-04520-4

Matsuguma, L. S., Lacerda, L. G., Schnitzler, E., Silva Carvalho Filho, M. A. da, Landi Franco, C. M., \& Demiate, I. M. (2009). Characterization of native and oxidized starches of two varieties of Peruvian carrot (Arracacia xanthorrhiza, B.) from two production areas of Paraná state, Brazil. Brazilian Archives of Biology 
and Technology, 52(3), 701-713. https://doi.org/10.1590/S151689132009000300022

Mehboob, S., Ali, T. M., Alam, F., \& Hasnain, A. (2015). Dual modification of native white sorghum (Sorghum bicolor) starch via acid hydrolysis and succinylation. LWT, 64(1), 459-467. https:// doi.org/10.1016/j.lwt.2015.05.012

Mehfooz, T., Ali, T. M., \& Hasnain, A. (2019). Effect of cross-linking on characteristics of succinylated and oxidized barley starch. Journal of Food Measurement and Characterization, 13(2), 1058-1069. https://doi.org/10.1007/s11694-018-00021-3

Menczel, J. D., \& Kohl, W. S. (2020). Differential scanning calorimetry (DSC) in fiber research. Thermal Analysis of Textiles and Fibers. LTD. https://doi.org/10.1016/b978-0-08-100572-9.00003-3

Min, S., Hongbo, T., \& Yanping, L. (2017). Synthesis, characterization and properties of acetylated high-amylose corn starch. Cellulose Chemistry and Technology, 51(9-10), 929-938.

Molavi, H., Razavi, S. M. A., \& Farhoosh, R. (2018). Impact of hydrothermal modifications on the physicochemical, morphology, crystallinity, pasting and thermal properties of acorn starch. Food Chemistry, 245, 385-393. https://doi.org/10. 1016/j.foodchem.2017.10.117

Monroy, Y., Rivero, S., \& García, M. A. (2018). Microstructural and techno-functional properties of cassava starch modified by ultrasound. Ultrasonics Sonochemistry, 42, 795-804. https://doi.org/ 10.1016/j.ultsonch.2017.12.048

Moreno, O., Cárdenas, J., Atarés, L., \& Chiralt, A. (2017). Influence of starch oxidation on the functionality of starch-gelatin based active films. Carbohydrate Polymers, 178, 147-158. https://doi. org/10.1016/j.carbpol.2017.08.128

Morikawa, K., \& Nishinari, K. (2000). Rheological and DSC studies of gelatinization of chemically modified starch heated at various temperatures. Carbohydrate Polymers, 43(3), 241-247. https:// doi.org/10.1016/S0144-8617(00)00148-X

Oderinde, A. A., Ibikunle, A. A., Bakre, L. G., \& Babarinde, N. A. A. (2020). Modification of African breadfruit (Treculia africana, Decne) kernel starch: Physicochemical, morphological, pasting, and thermal properties. International Journal of Biological Macromolecules, 153, 79-87. https://doi.org/10.1016/j.ijbiomac. 2020.02.293

Oh, S. M., Kim, H., yun, Bae, J. E., Ye, S. J., Kim, B. Y., Choi, H. D., et al. (2019). Physicochemical and retrogradation properties of modified chestnut starches. Food Science and Biotechnology, 28(6), 1723-1731. https://doi.org/10.1007/s10068-019-00622-8

Olayinka, F. S., Olayinka, O. O., Olu-Owolabi, B. I., \& Adebowale, K. O. (2015). Effect of chemical modifications on thermal, rheological and morphological properties of yellow sorghum starch. Journal of Food Science and Technology, 52(12), 8364-8370. https://doi.org/10.1007/s13197-015-1891-3

Okunlola, A., Adewusi, S. A. (2019). Development of Theophylline Microbeads Using PregelatinizedBreadfruit Starch (Artocarpus altilis) as a Novel Co-polymer for Controlled Release. Advanced Pharmaceutical Bulletin 9(1) 93-101. https://doi.org/10.15171/ apb.2019.012

Palanisamy, A., Deslandes, F., Ramaioli, M., Menut, P., Plana-Fattori, A., \& Flick, D. (2020). Kinetic modelling of individual starch granules swelling. Food Structure, 26, 100150. https://doi.org/ 10.1016/j.foostr.2020.100150

Park, E. Y., Ma, J. G., Kim, J., Lee, D. H., Kim, S. Y., Kwon, D. J., \& Kim, J. Y. (2018). Effect of dual modification of HMT and crosslinking on physicochemical properties and digestibility of waxy maize starch. Food Hydrocolloids, 75, 33-40. https://doi. org/10.1016/j.foodhyd.2017.09.017

Pietrzyk, S., Juszczak, L., Fortuna, T., Łabanowska, M., Bidzińska, E., \& Błoniarczyk, K. (2012). The influence of $\mathrm{Cu}(\mathrm{II})$ ions on physicochemical properties of potato starch oxidised by hydrogen peroxide. Starch/staerke, 64(4), 272-280. https://doi.org/10. 1002/star.201100090

Pineda-Gomez, P., González, N. M., Contreras-Jimenez, B., \& RodriguezGarcia, M. E. (2021). Physicochemical characterisation of starches from six potato cultivars native to the Colombian andean region. Potato Research, 64(1), 21-39.

Pratiwi, M., Faridah, D. N., \& Lioe, H. N. (2018). Structural changes to starch after acid hydrolysis, debranching, autoclaving-cooling cycles, and heat moisture treatment (HMT): A review. Starch/ Staerke, 70(1-2). https://doi.org/10.1002/star.201700028

Rahman, M. H., Mu, T. H., Zhang, M., Ma, M. M., \& Sun, H. N. (2020). Comparative study of the effects of high hydrostatic pressure on physicochemical, thermal, and structural properties of maize, potato, and sweet potato starches. Journal of Food Processing and Preservation, 44(11). https://doi.org/10.1111/jfpp.14852

Ren, F., \& Wang, S. (2019). Effect of modified tapioca starches on the gelling properties of whey protein isolate. Food Hydrocolloids, 93, 87-91. https://doi.org/10.1016/j.foodhyd.2019.02.025

Renzetti, S., van den Hoek, I. A. F., \& van der Sman, R. G. M. (2021). Mechanisms controlling wheat starch gelatinization and pasting behaviour in presence of sugars and sugar replacers: Role of hydrogen bonding and plasticizer molar volume. Food Hydrocolloids, 119, 106880. https://doi.org/10.1016/j.foodhyd.2021. 106880

Rincon-Aguirre, A., Mendoza-Diaz, S. O., \& Alicia del Real, M. E. R. G. (2018). Physicochemical studies of taro starch chemically modified by acetylation, phosphorylation, and succinylation. Starch-Stärke, 70, 1700066.

Román, L., Martínez, M. M., Rosell, C. M., \& Gómez, M. (2015). Effect of microwave treatment on physicochemical properties of maize flour. Food and Bioprocess Technology, 8(6), 1330-1335. https://doi.org/10.1007/s11947-015-1493-0

Schafranski, K., Ito, V. C., \& Lacerda, L. G. (2021). Impacts and potential applications: A review of the modification of starches by heat-moisture treatment (HMT). Food Hydrocolloids, 117, 106690. https://doi.org/10.1016/j.foodhyd.2021.106690

Schmiele, M., Sampaio, U. M., Gomes, P. T. G., \& Pedrosa Silva Clerici, M. T. (2018). Physical modifications of starch. Starches for Food Application: Chemical, Technological and Health Properties (eds.). Chapter 6, 223-269 https://doi.org/10.1016/B978-0-12809440-2.00006-X

Shah, N., Mewada, R. K., \& Mehta, T. (2016). Crosslinking of starch and its effect on viscosity behaviour. Reviews in Chemical Engineering, 32(2), 265-270. https://doi.org/10.1515/revce-2015-0047

Shaikh, M., Ali, T. M., \& Hasnain, A. (2017). Effects of different modification reagents on functional properties of pearl millet starches. Starch/staerke, 69(3-4), 1-10. https://doi.org/10.1002/ star.201600142

Shi, L., Zhong, L., Zhang, B., Fu, X., \& Huang, Q. (2020). Encapsulation and release characteristics of ethylene gas from V6- and V7-type crystalline starches. International Journal of Biological Macromolecules, 156, 10-17. https://doi.org/10.1016/j.ijbiomac. 2020.03.240

Shi, M., Zhang, M., Yang, L., Li, D., Yan, Y., Huang, X., \& Liu, Y. (2019). Effect of sodium chloride on the structure and properties of fried starch. Starch/staerke, 71(9-10), 1-24. https://doi.org/ 10.1002/star.201900014

Singh, M., \& Adedeji, A. A. (2017). Characterization of hydrothermal and acid modified proso millet starch. LWT - Food Science and Technology, 79, 21-26. https://doi.org/10.1016/j.lwt.2017.01.008

Singh, S., Raina, C. S., Bawa, A. S., \& Saxena, D. C. (2005). Effect of heat-moisture treatment and acid modification on rheological, textural, and differential scanning calorimetry characteristics of sweetpotato starch. Journal of Food Science, 70(6), e373-e378. https://doi.org/10.1111/j.1365-2621.2005.tb11441.x 
Sudheesh, C., Sunooj, K. V., \& George, J. (2019a). Kithul palm (Caryota urens) as a new source of starch: Effect of single, dual chemical modifications and annealing on the physicochemical properties and in vitro digestibility. International Journal of Biological Macromolecules, 125, 1084-1092. https://doi.org/ 10.1016/j.ijbiomac.2018.12.179

Sudheesh, C., Sunooj, K. V., George, J., Kumar, S., \& Vikas, \& Sajeevkumar, V. A. (2019b). Impact of $\gamma$ - irradiation on the physico-chemical, rheological properties and in vitro digestibility of kithul (Caryota urens) starch; a new source of nonconventional stem starch. Radiation Physics and Chemistry, 162, 54-65. https://doi.org/10.1016/j.radphyschem.2019.04.031

Sujka, M. (2017). Ultrasonic modification of starch - Impact on granules porosity. Ultrasonics Sonochemistry, 37, 424-429. https://doi.org/10.1016/j.ultsonch.2017.02.001

Thomaz, L., Ito, V. C., Malucelli, L. C., da Silva Carvalho Filho, M. A., Demiate, I. M., Bet, C. D., et al. (2020). Effects of dual modification on thermal, structural and pasting properties of taro (Colocasia esculenta L.) starch. Journal of Thermal Analysis and Calorimetry, 139(5), 3123-3132. https://doi.org/10.1007/s10973-019-08728-1

Thys, R. C. S., Aires, A. G., Marczak, L. D. F., \& Noreña, C. P. Z. (2013). The effect of acid hydrolysis on the technological functional properties of pinhão (Araucaria brasiliensis) starch. Food Science and Technology, 33, 89-94. https://doi.org/10. 1590/S0101-20612013000500014

Ulbrich, M., \& Flöter, E. (2019). Functional properties of acidthinned potato starch: Impact of modification, molecular starch characteristics, and solution preparation. Starch/staerke, 71(11-12), 1-11. https://doi.org/10.1002/star.201900176

Vanier, N. L., Pozzada dos Santos, J., Pinheiro Bruni, G., \& Zavareze, E. da R. (2019). Starches in foods and beverages. Handbook of Eating and Drinking, 1-17. https://doi.org/10. 1007/978-3-319-75388-1_132-1

Vermeylen, R., Goderis, B., Reynaers, H., \& Delcour, J. A. (2005). Gelatinisation related structural aspects of small and large wheat starch granules. Carbohydrate Polymers, 62(2), 170181. https://doi.org/10.1016/j.carbpol.2005.07.021

Wang, H., Xiao, N., Wang, X., Zhao, X., \& Zhang, H. (2019a). Effect of pregelatinized starch on the characteristics, microstructures, and quality attributes of glutinous rice flour and dumplings. Food Chemistry, 283, 248-256. https://doi.org/10.1016/j.foodchem. 2019.01.047.

Wang, M., Sun, M., Zhang, Y., Chen, Y., Wu, Y., \& Ouyang, J. (2019b). Effect of microwave irradiation-retrogradation treatment on the digestive and physicochemical properties of starches with different crystallinity. Food Chemistry, 298, 125015. https://doi.org/10.1016/j.foodchem.2019.125015

Wang, R., Wan, J., Liu, C., Xia, X., \& Ding, Y. (2019c). Pasting, thermal, and rheological properties of rice starch partially replaced by inulin with different degrees of polymerization. Food Hydrocolloids, 92, 228-232. https://doi.org/10.1016/j. foodhyd.2019.02.008

Wang, S., Zhang, X., Wang, S., \& Copeland, L. (2016). Changes of multi-scale structure during mimicked DSC heating reveal the nature of starch gelatinization. Scientific Reports, 6, 1-9. https://doi.org/10.1038/srep28271

Wang, X., Huang, L., Zhang, C., Deng, Y., Xie, P., Liu, L., \& Cheng, J. (2020). Research advances in chemical modifications of starch for hydrophobicity and its applications: A review. Carbohydrate Polymers, 240, 116292. https://doi.org/10.1016/j. carbpol.2020.116292

Wilpiszewska, K., Antosik, A. K., \& Zdanowicz, M. (2019). The effect of citric acid on physicochemical properties of hydrophilic carboxymethyl starch-based films. Journal of Polymers and the Environment, 27(6), 1379-1387. https://doi.org/10. 1007/s10924-019-01436-9
Xu, M., Saleh, A. S. M., Gong, B., Li, B., Jing, L., Gou, M., et al. (2018). The effect of repeated versus continuous annealing on structural, physicochemical, and digestive properties of potato starch. Food Research International, 111, 324-333. https://doi. org/10.1016/j.foodres.2018.05.052

Yan, H., \& Zhengbiao, G. U. (2010). Morphology of modified starches prepared by different methods. Food Research International, 43(3), 767-772. https://doi.org/10.1016/j.foodres.2009.11.013

Yang, C., Zhong, F., Douglas Goff, H., \& Li, Y. (2019a). Study on starch-protein interactions and their effects on physicochemical and digestible properties of the blends. Food Chemistry, 280, 51-58. https://doi.org/10.1016/j.foodchem.2018.12.028

Yang, W., Kong, X., Zheng, Y., Sun, W., Chen, S., Liu, D., et al. (2019b). Controlled ultrasound treatments modify the morphology and physical properties of rice starch rather than the fine structure. Ultrasonics Sonochemistry, 59, 104709. https:// doi.org/10.1016/j.ultsonch.2019.104709

Zeng, F., Li, T., Gao, Q., Liu, B., \& Yu, S. (2018). Physicochemical properties and in vitro digestibility of high hydrostatic pressure treated waxy rice starch. International Journal of Biological Macromolecules, 120, 1030-1038. https://doi.org/10.1016/j. ijbiomac.2018.08.121

Zhang, K., Dai, Y., Hou, H., Li, X., Dong, H., Wang, W., \& Zhang, H. (2019a). Influences of grinding on structures and properties of mung bean starch and quality of acetylated starch. Food Chemistry, 294(61), 285-292. https://doi.org/10.1016/j.foodchem.2019.05.055

Zhang, Q., Zhang, S., Deng, L., Wu, C., \& Zhong, G. (2018). Effect of vacuum treatment on the characteristics of oxidized starches prepared using a green method. Starch/staerke, 70, 1700216. https:// doi.org/10.1002/star.201700216

Zhang, X., Ma, Q., Liu, X., Zhang, D., Ma, L., Luo, D. L., \& Liu, X. (2020). Effect of microwave irradiation on the pasting, thermal, and rheological properties of cassava starch-sugar mixtures. Journal of Food Process Engineering, 43(8), 1-8. https://doi.org/10.1111/jfpe.13431

Zhang, X., Shen, Y., Zhang, N., Bao, J., Wu, D., \& Shu, X. (2019b). The effects of internal endosperm lipids on starch properties: Evidence from rice mutant starches. Journal of Cereal Science, 89, 102804. https://doi.org/10.1016/j.jcs.2019.102804

Zhang, Y. R., Wang, X. L., Zhao, G. M., \& Wang, Y. Z. (2012). Preparation and properties of oxidized starch with high degree of oxidation. Carbohydrate Polymers, 87(4), 2554-2562. https:// doi.org/10.1016/j.carbpol.2011.11.036

Zhang, Z. H., Wang, L. H., Zeng, X. A., Han, Z., \& Brennan, C. S. (2019c). Non-thermal technologies and its current and future application in the food industry: A review. International Journal of Food Science and Technology, 54(1), 1-13. https://doi. org/10.1111/ijfs.13903

Zhu, F., \& Li, H. (2019). Modification of quinoa flour functionality using ultrasound. Ultrasonics Sonochemistry, 52, 305-310. https://doi.org/10.1016/j.ultsonch.2018.11.027

Zhu, F., \& Liu, P. (2020). Starch gelatinization, retrogradation, and enzyme susceptibility of retrograded starch: Effect of amylopectin internal molecular structure. Food Chemistry, 316, 126036. https://doi.org/10.1016/j.foodchem.2019.126036

Zia-ud-Din, Xiong, H., \& Fei, P. (2017). Physical and chemical modification of starches: A review. Critical Reviews in Food Science and Nutrition, 57(12), 2691-2705. https://doi.org/10. 1080/10408398.2015.1087379

Zuo, Y., Liu, W., Xiao, J., Zhao, X., Zhu, Y., Wu, Y. (2017). Preparation and characterization of dialdehyde starch by one-step acid hydrolysis and oxidation. International Journal of Biological Macromolecules 1031257-1264. https://doi.org/10.1016/j.ijbiomac.2017.05. 188

Publisher's Note Springer Nature remains neutral with regard to jurisdictional claims in published maps and institutional affiliations. 